\title{
ARQUEOLOGÍA DE LOS PERIODOS ALTIPLANO E INCA EN SANDIA Y CARABAYA, AL NORTE DE LA CUENCA DEL TITICACA - PERÚ
}

\author{
LUIS FLORES BLANCO \\ Universidad Complutense de MADRID / Universidad NACIONAL MAYor de SAN Marcos \\ luflores@estumail.ucm.es Iflores78@gmail.com \\ CÉsAR CoRnejo MAYa \\ UnIVERSIDAD NACIONAL MAYOR DE SAN MARCOS \\ maya_1746@yahoo.es \\ DANIEL CÁCEdA GUILLÉN \\ UNIVERSIDAD NACIONAL MAYOR DE SAN MARCOS \\ danielcaceda@gmail.com
}

\section{RESUMEN}

Los autores entregan información sobre su visita por las regiones de Carabaya y Sandia, describiendo once sitios arqueológicos tardíos; la mayor parte es información inédita para la arqueología Andina. Esta publicación intenta dar algunas luces, y resaltar la potencialidad que tiene el estudio del pasado, desde la parte oriental del actual Puno, para entender el desarrollo de importantes culturas como las del período Altiplano y la Inka.

Palabras Clave: Andes, Puno, Altiplano, Sandia, Carabaya, Inka, Intermedio Tardío, cuenca del Titicaca.

\section{AbSTRACT}

The authors provide information about your visit to the regions of Sandia and Carabaya, describing eleven late archaeological sites, most of it is new information for Andean archaeology. This publication aims to provide some insight, and highlight the potential of studying the past, from the eastern part of the current Puno, to understand the development of important cultures such as the Altiplano and the Inka period.

Keywords: Andes, Puno, Altiplano, Sandia, Carabaya, Inka, Late Intermediate, Titicaca basin. 
Algunos pasos más y ya habría salido de la silvestre provincia de Carabaya; de aquella sin par región donde parece atropellarse la vida animal con la vida vegetal; donde la Naturaleza es reina absoluta y el ser humano un ser débil e impotente.

Antonio Raimondi (1874: 202)

Las provincias de Sandia y Carabaya, al norte de la cuenca del Titicaca, son las puertas de acceso a la zona selvática para el altiplano puneño, lo cual los convierte en una región de importancia, si pensamos en una estrategia política y económica de control vertical de pisos ecológicos como lo entendió John Murra (1975).

Coben y Stanish (2005) han venido deduciendo que así como la región de Carabaya fue un lugar de extracción de oro para los españoles, también lo fue para el imperio Inka. En esa misma lógica, creemos que la región de Sandia también habría cumplido el mismo rol que Carabaya, lo que convertiría al oriente puneño en una región geopolítica y económicamente estratégica y atractiva para el crecimiento del imperio Inka, y seguramente antes para el desarrollo de la riqueza de las grandes sociedades complejas agro-pastoriles del periodo Altiplano (tal como lo entiende Stanish 2003).

A pesar de la importancia para la arqueología andina, la región más allá de la cordillera de Carabaya ha sido relegada si lo comparamos con la investigación alrededor de la cuenca del Titicaca (Flores y Tantaleán 2012; Stanish 2003).

Queremos llamar la atención, con este artículo, el potencial que tienen estas regiones para explicar, desde un punto de vista periférico, problemas como el desarrollo de las sociedades complejas del periodo Intermedio Tardío y las estrategias de dominio de los Incas en el Altiplano.

Fuentes etnohistóricas, orales e historias locales coinciden en afirmar que la zona de Carabaya, Sandia e incluso la región de Larecaja, en el norte boliviano, fue el territorio de una nación llamada Callahuaya, cuyos pobladores fueron pastores, viajeros, pero sobre todo recordados por sus dotes de curanderos (Ávila 2005; Dueñas 1975); y sus tierras reconocidas por su riqueza aurífera, tan importante que primero los Incas la adscribieron a sus dominios como parte del Antisuyo, y durante la Colonia, la Corona española exploró y explotó estos territorios (Guamán Poma de Ayala 2005 [1615]; Garcilaso de la Vega 2005 [1606]).

A pesar de la gran importancia descrita son casi nulas las investigaciones que se han llevado a cabo en la zona, sobre todo en Sandia, salvo algunos estudios de impacto arqueológico practicados en la zona (Edmundo de la Vega com. pers. 2010).

Las primeras referencias contemporáneas, que se conoce de la región, son las extensas visitas de Antonio Raimondi $(1876,1887)$, quien resalta constantemente la presencia del oro en la región y la importancia que habría tenido para nuestra historia. Pero, también encontramos referencias importantes en los textos de Sir Clements R. Markham, Erland Nordeskiold (1953), Augusto Weberbauer, J.C. Spahni (1971), para citar a los principales. Además, se dieron esfuerzos particulares de gente local por conocer la historia de su región, quienes llegaron a describir muchos de sus monumentos y narraron varias de sus tradiciones, tenemos así los trabajos de José Franco Inojosa (1936), Samuel Frisancho Paredes (1983), Nicolás Luna Peralta (1999), Juan Palao Berastain (1991), Amador Quispe, Lorgio Quispe y José Quispe (1995), Félix Tapia (1985), Benjamín Dueñas (1975) y Walter Ávila (2005).

Recientemente, Carabaya ha alcanzado fama mundial por el hallazgo de una muestra impresionante de arte rupestre (Hostnig 2003a, 2003b), que a decir de su mayor investigador «[es] una de las galerías de arte rupestre milenario más fascinantes y menos conocidos de los Andes peruanos» (Hostnig 2004: 14).

Mejor suerte ha tenido Carabaya. En los últimos años se ha empezado algunas investigaciones sobre esta región, reportándose evidencias de varios sitios tardíos acomodados a una accidentada topografía (Coben y Stanish 2005; Conlee et al. 2004). 
Hace pocos años, además, se publicó un compendio sobre la historia general de Carabaya, que resulta ser el primer trabajo de síntesis para la zona (Hostnig 2010). Más recientemente, tenemos los trabajos del proyecto Qapaq Ñan, del Ministerio de Cultura, que ha podido develar la compleja red de caminos en esta zona, tanto pertenecientes a los Incas, como para la ocupación previa, que permitía tener comunicado la cuenca del Titicaca con la costa pacífica (López 2012). Actualmente, también contamos con más evidencias de material cultural Colla e Inca, al menos en contextos funerarios, gracias a los proyectos de evaluación arqueológica, como parte de la construcción de la carretera interoceánica (Román y Román 2012).

Ante este panorama, este artículo representa un esfuerzo por rindar más información sobre la historia antigua de Sandia y Carabaya, a partir de un trabajo de reconocimiento superficial que realizamos en el año 2004 (Fig. 1). Si bien no contamos con una muestra representativa, por los pocos y

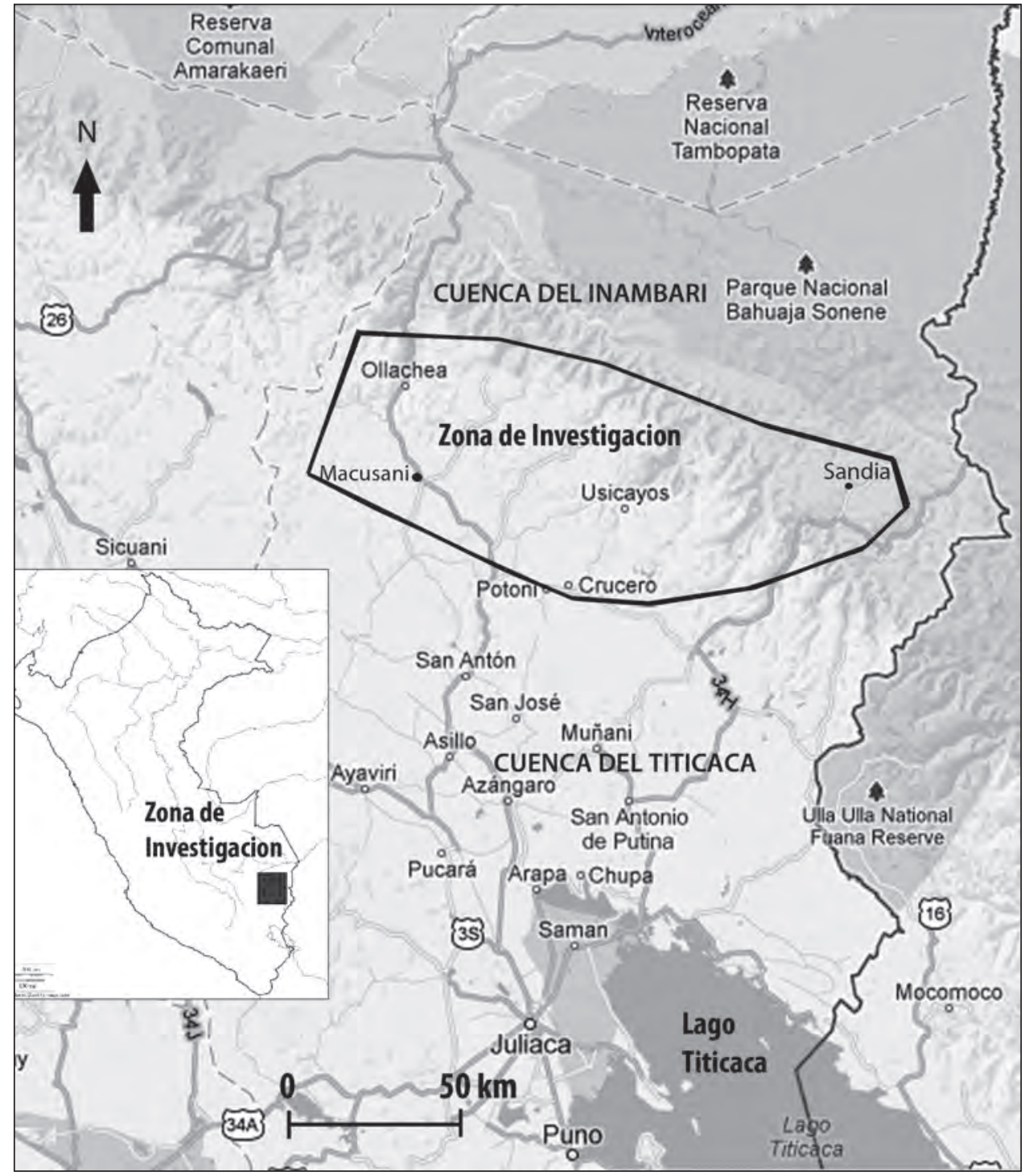

Figura 1. Mapa de ubicación del área investigada. 
concretos sitios visitados, sin recolección de material de superficie. El trabajo sólo consistió en levantar descripciones superficiales de los sitios, geoubicarlos con un navegador manual GPS, calcular el área, hacer croquis de los yacimientos y registrarlos fotográficamente (Flores y Cáceda 2004a; Cornejo y Flores 2004).

Gran parte de esta información ha sido dado a conocer recientemente en un artículo en ingles (Flores et al. 2012), no obstante, creemos conveniente su publicación en castellano para su difusión, pero además porque hemos actualizado nuestros antecedentes, ingresado información inédita recién procesada y enriquecido nuestra interpretación a partir de ellos.

\section{SANDia y CARABAyA: Aspectos INICIALES}

El departamento de Puno tiene $72.382 \mathrm{~km}^{2}$, de los cuales el 70\% es la altiplanicie del Collao, donde se ha centrado la mayor parte de las investigaciones arqueológicas; y el 30\% restante los constituyen los terrenos cordilleranos y la zona de selva que limita con Madre de Dios, ésta última separada del altiplano por la cordillera de Carabaya, que reparte el agua, en dirección sur, hacia el Titicaca, y hacia el norte, formando, entre otros, la cuenca del río Inambari, afluente del Madre de Dios, que desemboca en el río Madeira, y éste en el Amazonas (PEISA 2004; Ávila 2005).

Nuestro reconocimiento abarcó de manera muy superficial cuatro afluentes de la cuenca del Inambari, los ríos: Sandia, Usicayos, Coasa, Ayapata y San Gabán u Ollachea. No habiéndole recorrido otros afluentes como los ríos Upina y Blanco. Creemos que en el futuro debería abordarse prospecciones a partir de cada uno de los afluentes del Inambari, que a nuestro parecer fueron corredores político-económicos durante la prehistoria de esta región.

A través de este territorio se puede acceder a diversos pisos ecológicos. De Sur a Norte se parten de zonas montañosas de topografía agreste, propia de la cordillera de Carabaya, cubierto por una foresta de extensos pajonales y zonas de vida propia de páramos pluviales subalpinos; bajando a una estrecha franja quechua y luego a amplias zonas de yunga fluvial con matorrales húmedos y bosques pluviales como Sandia y Ollachea. Inmediatamente se llega a territorios de bosques húmedos de montaña, propias de selva alta o rupa rupa, como San Juan de Oro y Masiapo en Sandia; e incluso a zonas de selva baja con bosques muy húmedos de características subtropicales como Lanlacuni Bajo en Carabaya, y Oroya y Candamo en Sandia, solo por citar algunos ejemplos (PEISA 2004; Ávila 2005).

En esta vasta región, logramos registrar once sitios en total, cinco de ellos en Sandia y seis en Carabaya (Fig. 2). Somos consientes que se trata solo de una pequeña muestra de yacimientos tardíos; sin embargo, nos ha valido para darnos cuenta de la existencia de asentamientos extensos y de una organización especialmente compleja, que creemos se implantó, en gran medida, para explotar los recursos de la región y solventar necesidades económicas exteriores, primero de los Collas, luego los Incas y finalmente los españoles.

Pero la historia de esta región es muy extensa, aunque poco conocida, remontándose, al parecer, hasta periodos tan tempranos como el Arcaico (Flores y Cáceda 2004a; Craig et al. 2010) y con una continua ocupación durante los periodos siguientes (Hostnig 2010).

Con el fin de entender la organización de los asentamientos estudiados nos hemos valido de tres niveles de análisis: en primer lugar describimos cada uno de los edificios como unidad arquitectónica mínima (la unidad doméstica, el edificio público, la plaza, las collcas, las chullpas, etc.). En segundo lugar analizamos la organización global del asentamiento formado por el conglomerado de las unidades mínimas. Y finalmente, la disposición de los sitios en el paisaje.

Solo con fines didácticos, hemos dividido la descripción de los sitios a partir de su ubicación política actual, lo cual no significa su separación sociocultural en la antigüedad. 


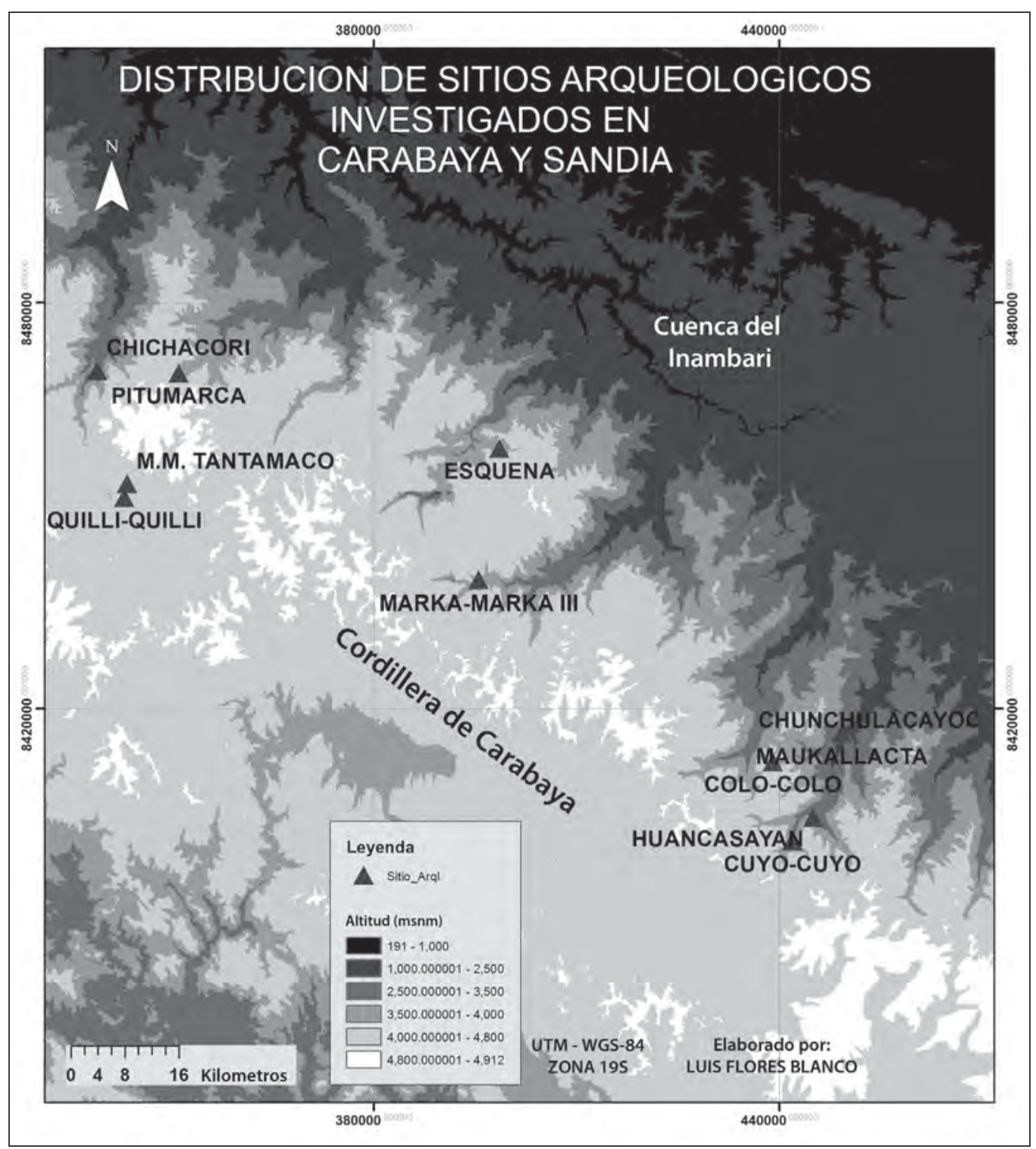

Figura 2. Mapa de distribución de los sitios arqueológicos investigados.

\section{Arqueología de Sandia}

Conseguimos visitar y registrar únicamente cinco evidencias arqueológicos en la provincia de Sandia, todos ellos de distintos tamaños, de los cuales sólo el de mayor área (Maukallacta) mostraba espacios amplios y especializados para ceremonias públicas y áreas domésticas diferenciadas. La mayoría de los demás casos son centros funerarios o centros poblados. Lo interesante es que todos los sitios están asentados sobre laderas aterrazadas o cimas niveladas de los cerros, bajo los cuales, y a cierta distancia (40 min de caminata en promedio), corren riachuelos. No hemos encontrado ningún fragmento diagnóstico de cerámica prehispánica u otro material que ayude a contextualizarlos, creemos debido al estado depredado que se encuentran, por su cercanía a los poblados y carreteras. 


\section{MAUKALLACTA}

Sitio asentado en la cima del cerro Chinchanaco, a 2850 msnm, en la margen izquierda del río Sandia, al sur de la quebrada de Chinchanaco y a 1,5 km al suroeste, en línea recta, de la ciudad actual de Sandia. El asentamiento también es conocido como Ch'iara-Pata (Nalvarte 1983: 123).

El sitio de Maukallacta cubre un área aproximada de 469.691,97 $\mathrm{m}^{2}$ (cerca de 47 hectáreas) y puede ser dividido en cuatro sectores (Fig. 3):

- El Sector A. Está formado por seis estructuras de uso funerario, llamadas comúnmente chullpas, todas de planta cuadrangular, de esquinas exteriores rectas, pero con acabados internos curvos. En promedio cada estructura tiene $9 \mathrm{~m}^{2}$ de espacio interior y con muros de piedra, de $2 \mathrm{~m}$ de altura. El techado es a base de falsa bóveda, cuyos lados sobresalen $0,8 \mathrm{~m}$ de las paredes y tiene más de un metro de altura. Todos los recintos tienen un único y pequeño acceso, y en algunos casos, se puede observar en el interior tarimas formadas por lajas planas que sobresalen 0,6 $\mathrm{m}$ de las paredes. En estas estructuras (Fig. 4) se aprecian varios restos humanos disturbados que demostraría un patrón de entierro múltiple.

- El Sector B. Corresponde a estructuras de mayores dimensiones, entre las cuales sobresale una plaza hundida de planta en forma ovalada irregular. Además hay diversos muros de uno y dos paramentos y recintos cuadrangulares.

En este sector, además de la plaza, destaca una estructura cuadrangular pequeña que presenta un acceso, tres ventanas y un nicho, el cual está circunscrito en otro recinto (Fig. 5).

Por la presencia de la plaza hundida y de la estructura cuadrangular con nicho, probablemente aquí se desarrollaron ceremonias públicas (en la plaza) y privadas (en el recinto). Además, por la presencia de algunos recintos cuadrangulares, asociados a dichas áreas públicas, y de factura bien lograda arquitectónicamente, nos haría pensar en posibles unidades residenciales de elite.

- El Sector C. Está formado por más de quince estructuras cuadrangulares y subcuadrangulares concentrados y que, en general, son ligeramente más grandes que las estructuras del Sector A. Su función es desconocida, pero por la forma y técnica, posiblemente, se traten de viviendas y depósitos. Su función exacta sólo se conocerá con excavaciones detalladas de sus pisos.

- El Sector D. Se sitúa en el extremo noreste del sitio y está formado por muros de contención, a manera de murallas, que rodean esta parte del asentamiento. Además, se han identificado algunas estructuras similares a las del Sector $C$.

El ordenamiento espacial de Maukallacta muestra una jerarquía espacial entre sus diversos sectores y una preocupación por resguardar el sitio con murallas. Además, para los pobladores del sitio fue importante contar con un espacio público para que parte de la población se reúna, posiblemente en festividades vinculada a los mallquis, ello explicaría la cercanía de las chullpas a la plaza.

\section{CHUNCHULACAYOC}

Asentamiento emplazado en la ladera del Cerro Queneque, a unos $1.950 \mathrm{msnm}$, ubicado en la confluencia (tingo) del río Sandia y la quebrada de Cahuanchaca. El sitio tiene un área de 56.630,22 $\mathrm{m}^{2}$ (más de 5 hectáreas) y dista aproximadamente, en línea recta, a 6,7 km, al noreste de la ciudad de Sandia. El asentamiento también ha sido denominado Q'awan-Chaka (Nalvarte 1983: 122)

Por la disposición de las estructuras, el sitio ha sido dividido en tres sectores, formado mayormente por unidades habitacionales y posiblemente algunos recintos de uso administrativo (Fig. 6). No llegamos a identificar el sector funerario, pero posiblemente, como nos mencionó el Sr. Luis Cabrera (teniente alcalde de la localidad), éste se halla al sur del sitio, en las laderas cercanas.

- El Sector A. Formado por aproximadamente 17 estructuras de planta cuadrangular y sub-cuadrangular, cada una de 3 x 3 m de lado en promedio. Los recintos en su mayor parte están contiguos y 


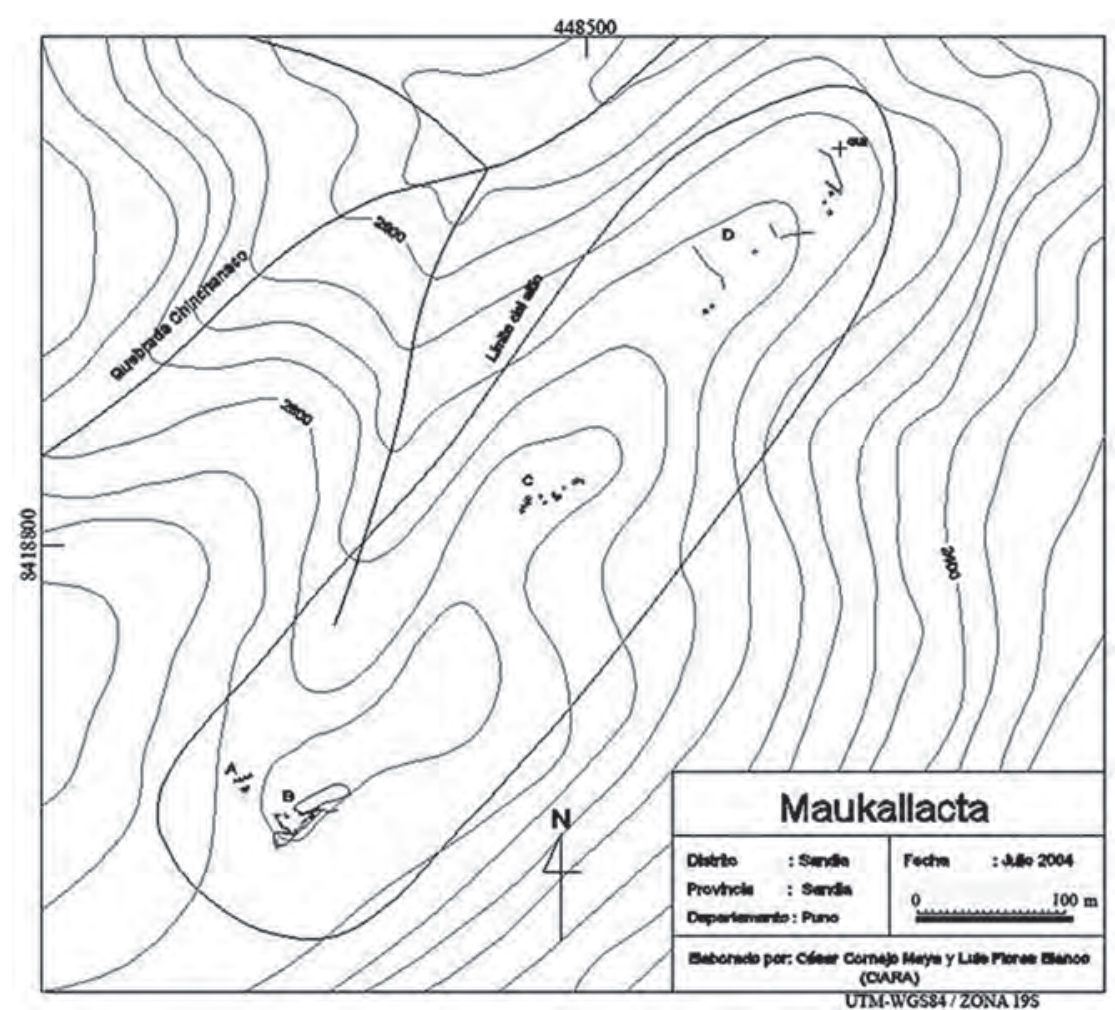

Figura 3. Plano del sitio Maukallacta.

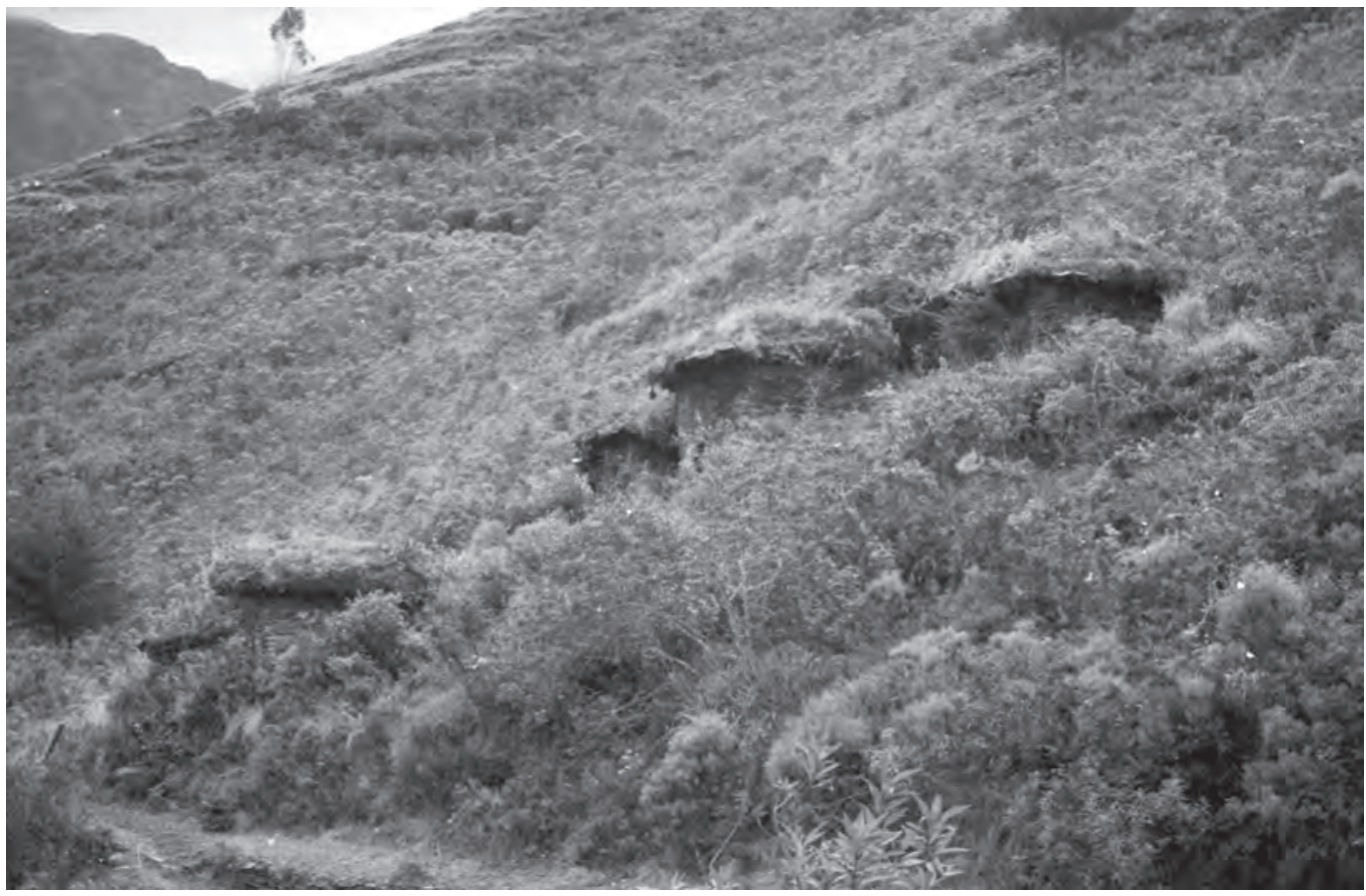

Figura 4. Recintos circulares (chullpas) en el sitio Maukallacta. 


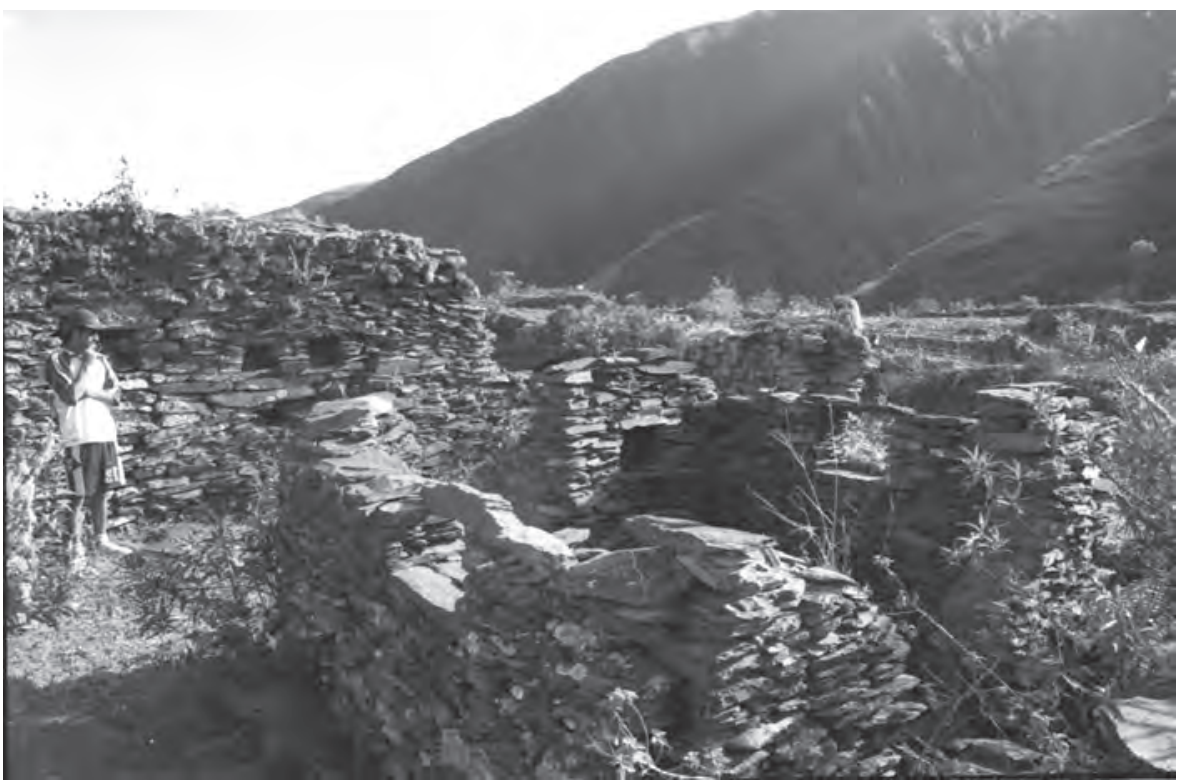

Figura 5. Recintos cuadrangulares con nichos en Maukallacta.

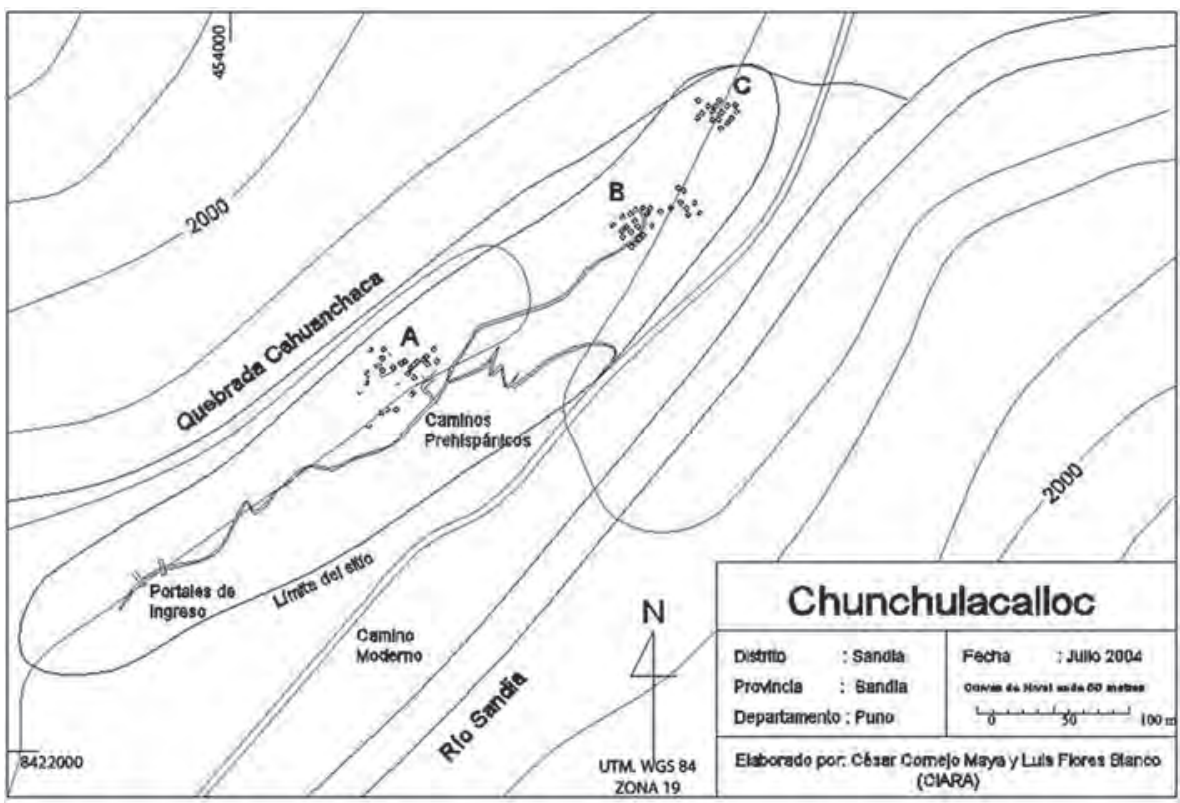

Figura 6. Plano del sitio Chunchulacalloc.

emplazados sobre terrazas bajas, de éstos nos llama la atención la más baja, sobre la cual se asienta una agrupación de siete estructuras, todas ellas rodeando un patio. Los recintos tienen muros de piedras cortadas unidas con barro y de una altura conservada de hasta 1,67 m. Algunas de las paredes presentan un nicho, y en un caso se observó una ventana compartida por dos recintos contiguos. De todas ellas, solamente una conserva su techo original que es de forma cónica y poco elevada (Figs. 7 y 8). 


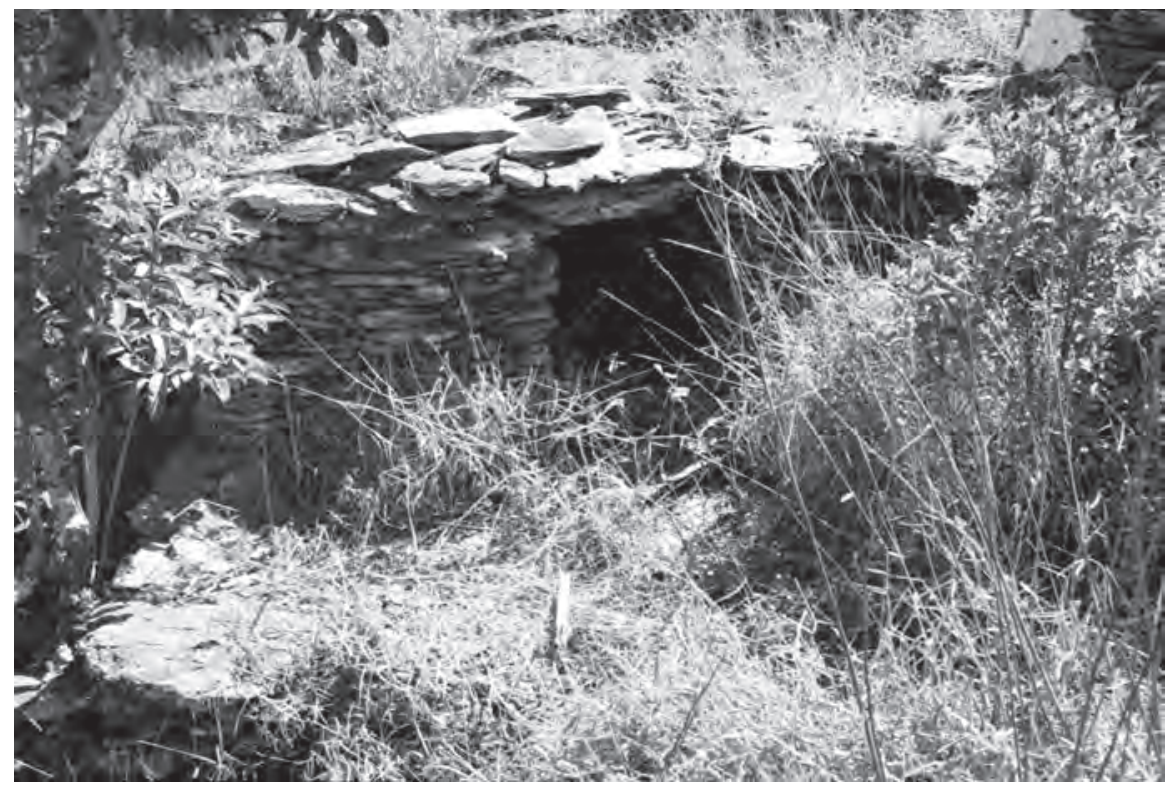

Figura 7. Recinto semihundido en Chunchulacayoc.

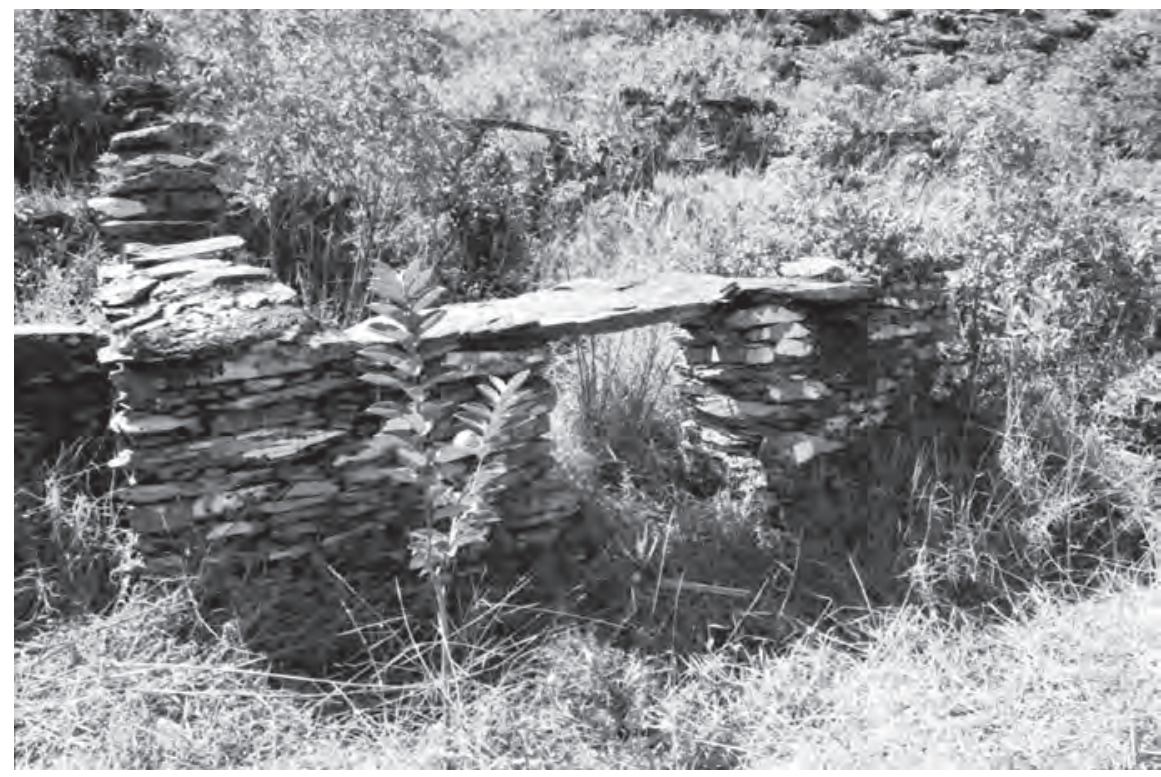

Figura 8. Recinto cuadrangular en Chunchulacayoc.

Otro tipo de construcción son cinco estructuras que se adosan al cerro, en el lado sureste, por lo cual, sólo están formadas por uno o dos muros, a manera de cercos.

Además, hay dos estructuras que rompen el patrón observado, y se asemejan más a construcciones incas, una de forma rectangular y otra que parecen ser dos estructuras contiguas comunicadas por medio de un acceso central.

En este sector se observa un camino empedrado de más de $2 \mathrm{~m}$ de ancho que se dirige hacia el suroeste, hasta la entrada al sitio, formada por dos portales de más de $2 \mathrm{~m}$ de altura. 
- El Sector B. Está conectado con el Sector A, por medio de la continuación del camino antes mencionado, que en este lado, en promedio, alcanza 1,1 m de ancho. Éste en realidad es una bifurcación del camino que llega desde la entrada al sitio, al suroeste del Sector A, pues el otro ramal desciende hacia el camino carrozable actual.

El sector está formado por aproximadamente 20 estructuras de características similares a las observadas en el Sector A. Si bien hay una similar cantidad, ellas están más concentradas, y algunas estructuras se sitúan en el borde de la escarpada ladera que se orienta hacia el río Sandia.

- El Sector C. No fue visitado, por falta de tiempo y su difícil acceso, pero desde el Sector B se pudo observar al menos otras siete estructuras de características similares a las observadas en los sectores A y B. Ellas se encuentran a menor altitud, sobre el promontorio que está junto a la confluencia de la quebrada Cahuanchaca con el río Sandia.

La presencia de una entrada formal y única al sitio de Chunculacayoc es una muestra de vigilancia del ingreso al sitio. Además la existencia de un solo camino empedrado a lo largo del sitio significa un control en la circulación. Teniendo evidencias de control en el ingreso y la circulación, sería normal encontrar murallas protectoras, pero no hay dichas evidencias, tal vez en parte debido a que la carretera Sandia - San Juan del Oro pudo afectarla o simplemente no la tuvo; sólo queda claro que la protección de los lados norte y oeste fue de manera natural, gracias a la presencia de pendientes abruptas.

El sector mejor registrado en el sitio fue el Sector A donde hemos notado tres tipos de espacios construidos. Uno de estos tipos nos resulta interesante destacar, el cual es una agrupación de recintos, muchos de ellos contiguos, alrededor de un patio común usados por el grupo doméstico. Dicho patrón nos hace recordar lo que Lavallee y Julien (1983: 49) llamaron «unidades alveolares» para el caso de los Asto en la sierra central.

Aparte de estos pequeños patios no hemos logrado identificar espacios abiertos de mayor tamaño, asignables a algún uso supra-domestico ó público.

\section{HUANCASAYAN o WANKA-SAYANI}

Pequeño sitio ubicado junto a la quebrada de Soniapo, en la margen izquierda del río Nacoreque, cerca al poblado de Huancasayani; esto es a $17 \mathrm{~km}$ al Sur de la ciudad de Sandia, a $3700 \mathrm{msnm}$.

El sitio es relativamente pequeño, tiene un área aproximada de 3.836,68 $\mathrm{m}^{2}$ (menos de media hectárea) y está formado por diez recintos individuales, de planta rectangular, que en promedio miden de $2,5 \mathrm{~m}^{2}$ a $4,5 \mathrm{~m}^{2}$.

Las estructuras se encuentran muy bien conservadas y se pudo observar el detalle de su secuencia constructiva. Primero se construyó una plataforma sólidamente rellenada de piedras y tierra, de $1 \mathrm{~m}$ de altura en promedio. Luego, se colocaron encima lajas a manera de piso, que incluso sobresalieron al área de la plataforma y finalmente se levantaron los muros con piedras medianas unidas con mortero de arcilla, mezclada con algunas piedrecillas molidas. Se termina la construcción con un techo cónico, abovedado, elaborado con piedras traslapadas (Fig. 9).

El sitio está organizado espacialmente con los recintos funerarios alrededor de un área abierta que habría funcionado como plaza.

Huancasayan está articulado a otras localidades mediante un camino que lo atraviesa por su lado oeste.

\section{ANDENES DE CUYO-CUYO}

Este extenso conjunto de andenes se encuentra a solo $3 \mathrm{~km}$ al sur del pueblo de Sandia. Es un paisaje cultural impresionante, pero que no pudimos estudiarlo intensivamente. Tiene una gran magnitud 


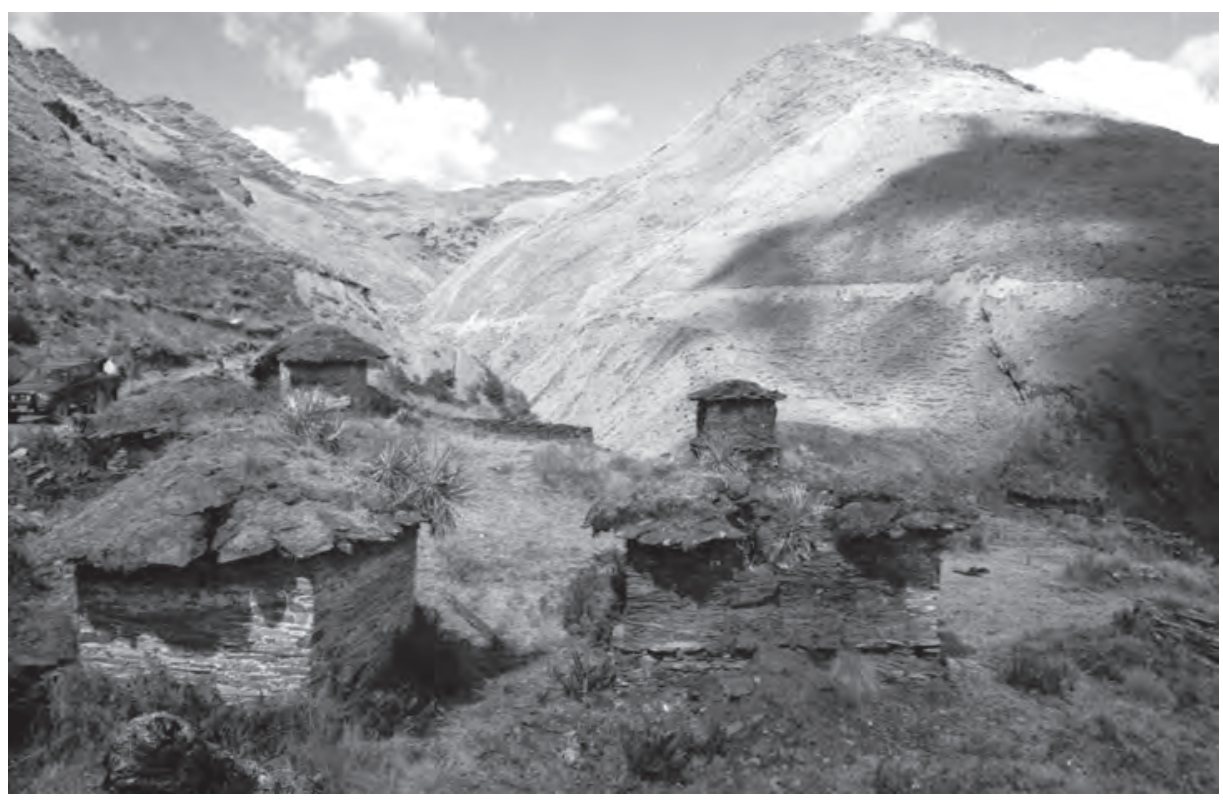

Figura 9. Conjunto de chullpas en el sitio Huancasayan.

(unos 4 km de largo ${ }^{1}$ ), y una bien lograda ingeniería de terrazas, que prácticamente tallan los cerros desde las laderas altas hasta cerca al rio, permitiendo tener terrenos desde los $2300 \mathrm{msnm}$ hasta superiores a los $3000 \mathrm{msnm}$ (Fig. 10).

La zona ha recibido atención de numerosos botánicos (Hodge 1951; Jackson et al. 1980; Jackson 2012), por la importancia de la domesticación y adaptación de tubérculos como la papa y la oca.

Jackson (2012) señala que las diferentes variedades de papas están adaptadas a diferentes niveles del valle, por tanto de la andenería. Las variedades más estimadas, con un contenido de materia seca, denominada harinosa o harinoso, se cultivaron en las terrazas superiores en los que había pocas posibilidades de inundación. Mientras que en el fondo del valle, que se inunda de vez en cuando, los agricultores cultivaban variedades que tienden a ser más «aguadas» y se utilizan preferentemente en las sopas.

Estamos convencidos que Cuyo-Cuyo debió haber funcionado como Moray en Cusco, es decir, como un verdadero centro de investigación de productos agrícolas. Este es un sitio que debería recibir mayor interés por los investigadores.

\section{COLO-COLO}

El asentamiento de Colocolo se sitúa en la ladera del cerro Pojoni, en la margen izquierda del río Patambuco, a 3300 msnm.

El conjunto arqueológico mide aproximadamente $35.508,18 \mathrm{~m}^{2}$ (3,5 hectáreas) y está formado por aproximadamente 80 estructuras, localmente llamadas chullpas, construidas sobre terrazas de piedra, cada una de las cuales contaban con espacios abiertos, ingresos y pasajes que permitía la comunicación entre terrazas. Algunas de estas chullpas fueron construidas aprovechando los promontorios rocosos, sobre todo en la parte alta del sitio (Fig. 11).

1 Según cálculos desde Google Earth 2012. 


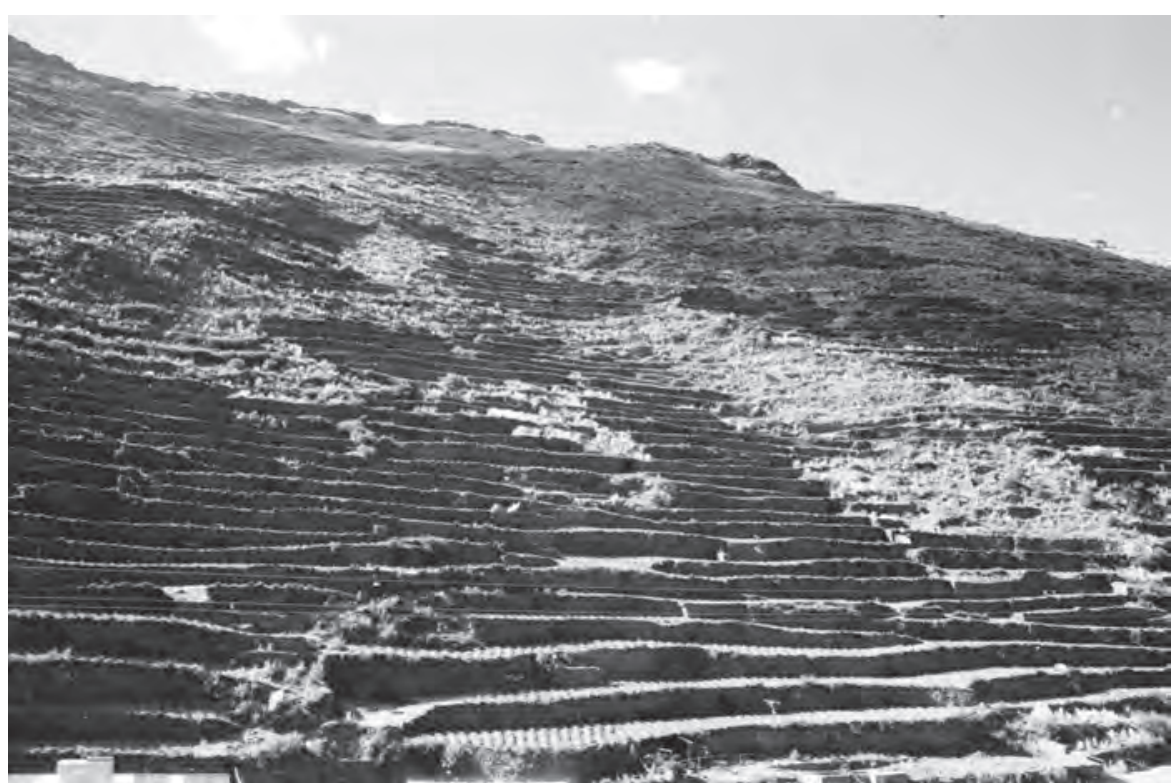

Figura 10. Vista de los andenes de Cuyo Cuyo.

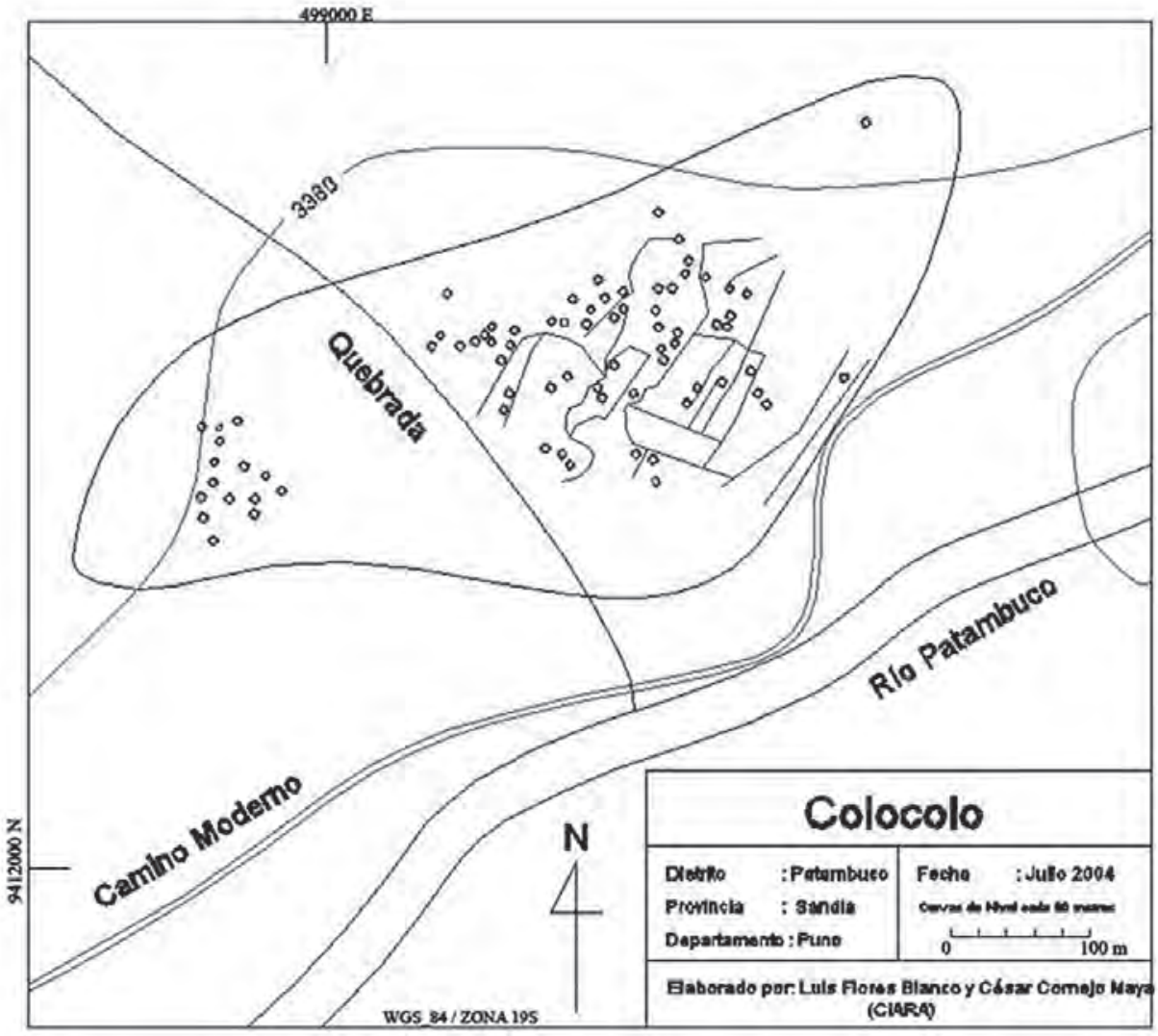

Figura 11. Plano del sitio Colocolo. 
Estas estructuras tienen una forma semi-cuadrangular y en promedio miden $3 \mathrm{~m}$ de lado, con vanos pequeños orientados mayormente al noreste, hacia los cerros, muy pocas hacia el valle y otras mirándose entre sí. Todas las estructuras estuvieron enlucidas con arcilla de color rojo, la misma que fue ya reportado por Isbell (1997: 164).

La mayoría de estructuras conservan su techo, el cual es de forma convexa y alcanza más de $1 \mathrm{~m}$ de altura (Fig. 12).

Además, en las laderas cercanas, se pueden observar otras estructuras de similares características, las cuales debido a lo difícil de su acceso y a la falta de tiempo, no fueron visitadas.

Popularmente se ha dado como un hecho, solo a partir de su forma, que la función de estos recintos son exclusivamente funerarios (chullpas), pero habría que evaluarlo mejor con excavaciones, así como por un preciso levantamiento topográfico y arquitectónico del sitio para saber que otras actividades, aparte de lo funerario, se llevaron a cabo en el asentamiento. Aunque Isbell (1968, 1997: 164) ha señalado que estos espacios estaban llenos de esqueletos.

Del mismo modo, nos llama la atención que este sitio no cuente con una plaza como sucede en Maukallacta y Huancasayan. Aunque esta falta de un espacio público común puede ser explicada si las actividades públicas no fueran comunales, sino más bien segmentadas; ello revelaría el por qué de la existencia de agrupaciones de recintos compartiendo el espacio abierto de una terraza.

Por otro lado, entre el río Patambuco y el camino actual existe un pueblo contemporáneo abandonado, sin embargo, algunas evidencias de construcciones subyacentes nos hacen pensar en la existencia de restos de un pueblo antiguo, tal vez se trate de lo que Nalvarte (1983: 125) ha llamado MayoPampa. Del mismo modo, recientemente se nos ha informado de un complejo arqueológico mayor, cercano, por encima del pueblo actual de Patambuco, llamado Trinchera Jarahuaña.

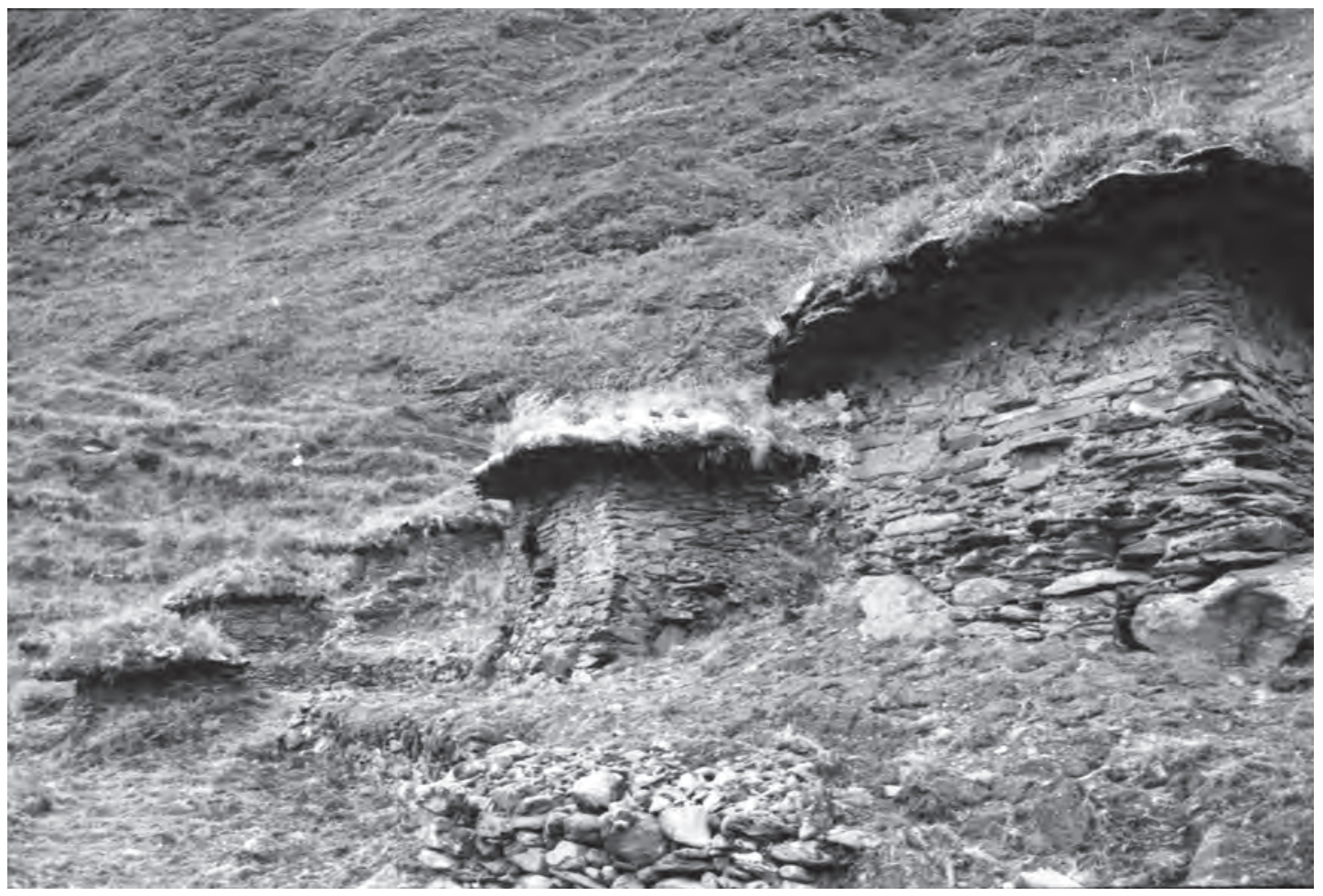

Figura 12. Vista de un par de estructuras (chullpas) en Colo-Colo. 


\section{OTROS SITIOS ARQUEOLÓGICOS EN SANDIA}

Tenemos referencias que existen otros sitios, por ejemplo en el distrito de Sandia, hay evidencias de chullpas en Q'awan-Chaka, Pata-Laqueque, Qéusani y Nacoreque-Chico; en Wayra-Ph'auchinta se han reportado pinturas rupestres (Nalvarte 1983: 122-123). En el distrito de Cuyo Cuyo hay una ciudadela preinca llamada Ph'utuni-Pata (Nalvarte 1983: 124). En el distrito de Patambuco hay varios asentamientos con características de pukaras o «fortalezas» como Pukara-Pata y Chuncho-Pukara; también hay chullpas y grandes monolitos entre la vegetación boscosa en Tira-Waka; finalmente en el sitio Harawaña hay chullpas, andenes y monolitos. En el distrito de Phara se reporta restos de viviendas pequeñas, chullpas y cercos a manera de fortificaciones en Chamapola (Nalvarte 1983: 127). En Limbani, en el sitio Mauq'a-Limbani se presentan construcciones de piedra y barro, como galpones de techos a dos aguas y chullpas con techos de lajas (Nalvarte 1983: 127). En el distrito de Quiaca también se señalan evidencias de chullpas para el sitio de Pukara-Pata ó Miraflores (Nalvarte 1983: 128).

\section{Arqueología de Carabaya}

Nuestro recorrido por la provincia de Carabaya nos permitió visitar seis de los diez distritos de Carabaya (Macusani, Corani, Ollachea, Ayapata, Coasa, Usicayos). La mayor concentración de sitios registrados fue en la cuenca del Ollachea o San Gabán, como Marca Marca de Tantamaco, Quilli Quilli y Chillacori. En la cuenca del Ayapata visitamos sólo el sitio de Pitumarca que por su complejidad nos recuerda los relatos de los sitios de Larecaja en Bolivia. En Coasa recorrimos las Chullpas de Esquena y el sitio de Huatamarca. Finalmente en Usicayos reconocimos el sitio de Marca Marca III.

Al igual que en Sandia, en Carabaya se repite el hecho que todos los sitios explorados están asentados sobre las faldas aterrazadas o cumbres niveladas de los cerros, bajo los cuales y a cierta distancia corren riachuelos.

A diferencia de Sandia, en Carabaya si hemos encontrado algunos fragmentos diagnósticos de cerámica, tanto en superficie como en los depósitos de la municipalidad de Usicayos. La mayor parte de los fragmentos muestra vinculación con el periodo Altiplano y con lo Inka. Mención aparte merece, lo que nos mostraron en el pueblo de Usicayos, un fragmento de vaso de madera, con escultura felínica, de claras características Tiwanaku (Fig. 13).

\section{MARCA MARCA DE TANTAMACO}

Se ubica al Norte y por encima del centro poblado de la comunidad de Tantamaco, a $4241 \mathrm{msnm}$.

El sitio arqueológico se asienta sobre un terreno aterrazado. Las estructuras presentan como material constructivo la piedra cortada, asentadas con un mortero de barro. Los recintos pueden presentar dos tipos de planta: una circular o semicircular (al parecer local) y otra rectangular (Inka);

El reconocimiento arqueológico ha podido definir cuatro sectores:

- Sector A. Constituido por una plaza grande en cuyo lado sur se ubica un recinto de planta rectangular, de 13,80 $\mathrm{m}$ de largo y 5,50 $\mathrm{m}$ de ancho. Algunas hornacinas interiores de forma trapezoidal de 0,38 $\mathrm{m}$ de ancho, 0,55 $\mathrm{m}$ de alto y 0,30 de profundidad se conservan en el paramento, del lado sur del recinto.

Otras estructuras rectangulares se encuentran asociadas a esta plaza. Los elementos arquitectónicos siguen una influencia Inka, y su función estaría vinculada a actividades públicas y administrativas.

- Sector B. En las afueras de la plaza del sector A, hacia el lado norte, se encuentran recintos de planta circular, que en un promedio alcanzan 3,30 m de diámetro. Su distribución puede ser aislada o aglutinados; en este último caso podemos encontrar pequeños pasajes que están conectando la circulación entre dichos recintos. 


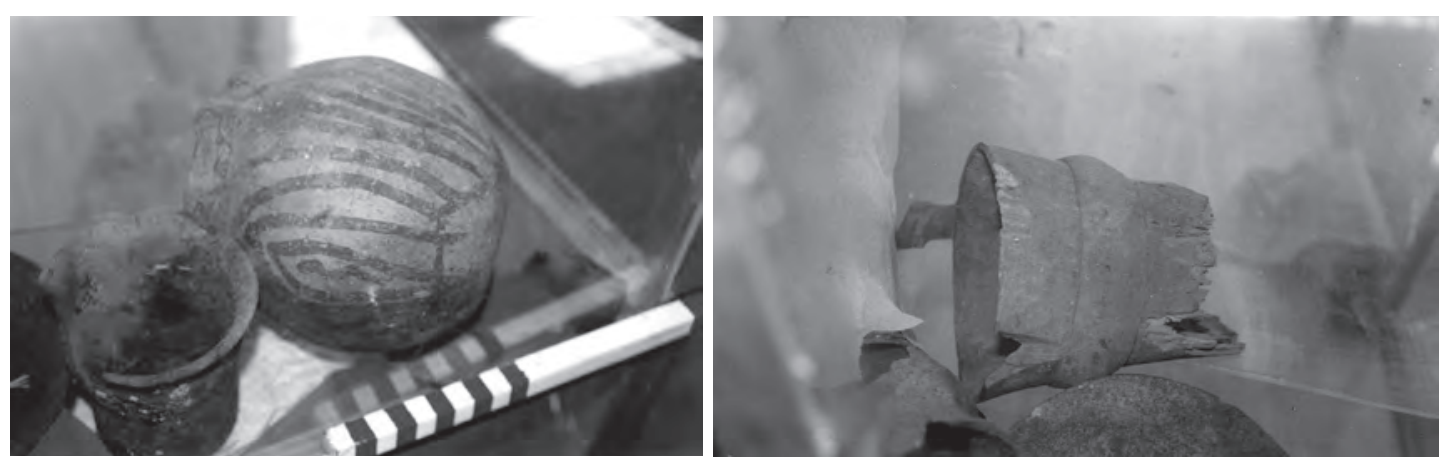

Figura 13. Material arqueológico en las vitrinas del Museo Municipal de Usicayos, nótese la cerámica de filiación Colla en la izquierda y el fragmento de vaso de madera Tiwanaku en la derecha.

- Sector C. Formado por una gran roca localizada en la parte más alta del asentamiento. Sobre ella, los actuales habitantes de Tantamaco han colocado una cruz cristiana. Esta roca mide $5 \mathrm{~m}$ de largo, 2,5 $\mathrm{m}$ de ancho en uno de sus lados, 0,60 $\mathrm{m}$ en el otro y $2 \mathrm{~m}$ en su punto de mayor altura. En uno de los bordes superiores de la roca, se han conservado los restos de dos hornacinas formadas por mampostería de piedras medianas. Alrededor, encontramos edificaciones juntas y abiertas, divididas y delimitadas por muros de piedra.

Por las evidencias halladas, creemos que este sector estuvo reservado para actividades ceremoniales de carácter mágico religioso. Los espacios abiertos están sugiriendo que en ellos se congregaban una cantidad considerable de personas, quienes asistían hasta aquí para ser partícipes de dichas actividades.

- Sector D. Este sector estaría definido por cámaras funerarias al pie de los afloramientos rocosos. En la superficie se puede observar cerámica fragmentada Inca local, caracterizado por formas de escudillas con diseños Cusco tipo B.

Por otro lado, hacia el extremo este del asentamiento se identificó un depósito de basura. La capa es de color marrón oscuro, propio de la descomposición orgánica, y alcanza un espesor de 0,6 m, y está conformada por fragmentos de cerámica, textiles, restos óseos de camélidos y material botánico diverso.

\section{QUILLI-QUILLI}

A 30 minutos de camino de la comunidad de Tantamaco, con dirección norte, se encuentra el sitio arqueológico de Quilli Quilli, emplazado en la margen derecha de la quebrada del mismo nombre, sobre dos promontorios rocosos que afloran en las faldas del cerro Quilla Quillisenja.

El sitio se distribuye sobre una ladera aterrazada, lograda en una pendiente abrupta, a $3942 \mathrm{msnm}$. La planta rectangular y cuadrangular es la que se ha podido observar en la mayoría de los recintos y los espacios abiertos, como plazas y patios, se encuentran delimitados por muros que pueden alcanzar hasta 1,40 m de espesor (Fig. 14).

En el recorrido realizado se ha podido distinguir preliminarmente dos grandes sectores o mitades, divididos por una calle de 1,5 a $2 \mathrm{~m}$ de ancho que sigue una dirección norte-sur. Este camino resulta de la unión de tres vías, uno de ellos viene del Norte, de dirección oriental, otro llega del Oeste, al parecer de Corani, y el último de Tantamaco (Quispe et al. 1995: 47).

- Sector A ó Mitad Baja. Está formado por construcciones en piedra canteada, entre las que destacan varias y amplias plazas, asociadas a estructuras rectangulares o cuadrangulares, al parecer para actividades administrativas y ceremoniales. 


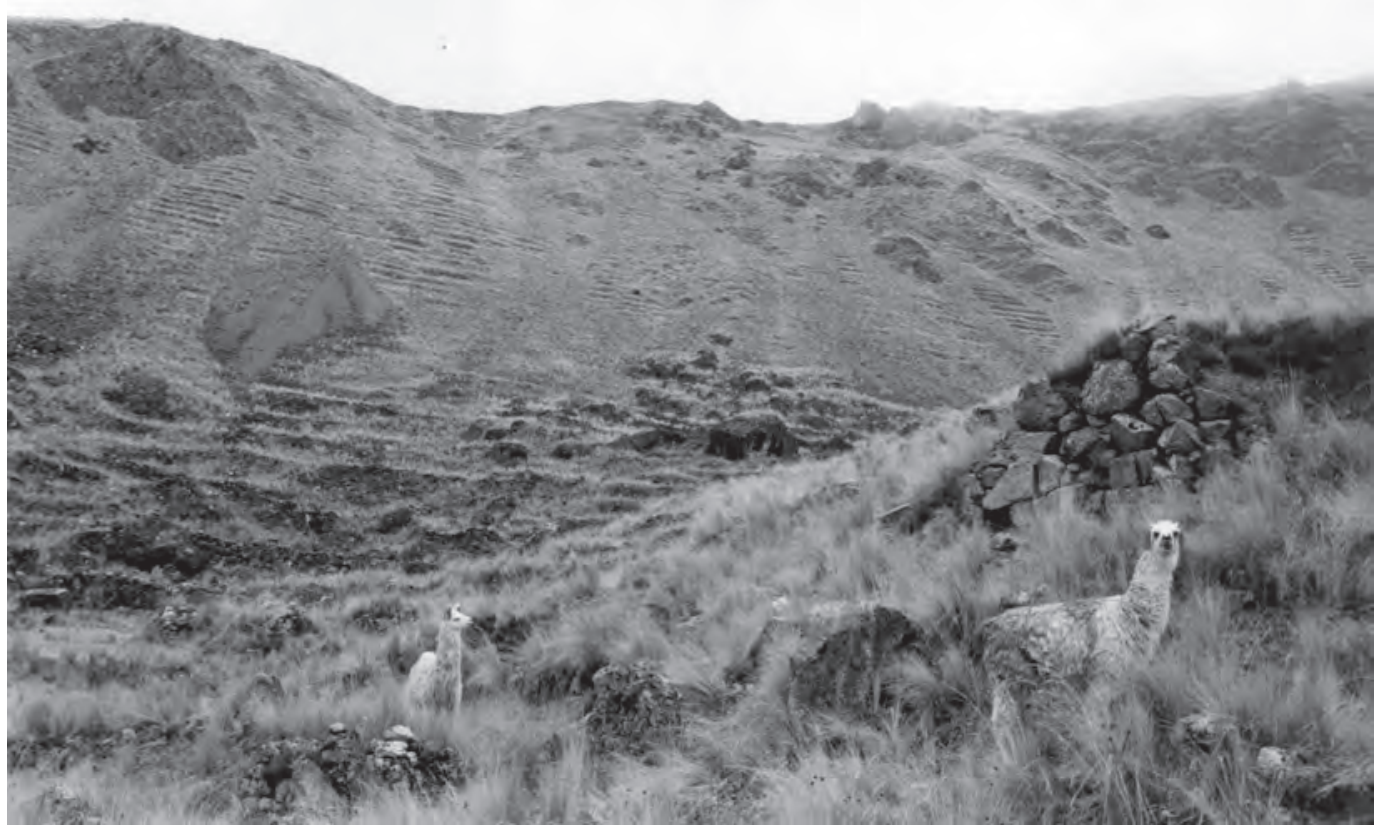

Figura 14. Vista panorámica del sitio Quilli-Quillide cubierto con grama.

- Sector B ó Mitad Alta. En el área más próxima al camino, hacia la parte superior del sitio, existe una serie de recintos concentrados alrededor de pequeñas plazuelas, ambas de formas redondeadas. Más arriba encontramos una serie de cámaras funerarias, logradas por la excavación de hoyos a los pies de los afloramientos rocosos, donde se colocaron los entierros, a manera de cavernas funerarias, asociadas a patios o pequeñas plazas aterrazadas y delimitadas por muros de doble cara. Algunos de estos afloramientos tenían figuras geométricas simples, seguro como especie de marcadores. Este diseño del espacio, patios asociados a contextos funerarios, así como marcas de pinturas rupestres, nos permite inferir la importancia del ritual alrededor de los muertos.

Coben y Stanish (2005: 274) han señalado que esta diferenciación, notada también por nosotros, en la forma de la planta y el tipo de arquitectura de las estructuras en la parte baja y alta del asentamiento, al igual que en la distribución de cerámica, permite interpretar que existe una ocupación y remodelación Inka sobre el sitio.

Dentro del material de superficie se ha identificado fragmentos de cerámica de pasta roja - anaranjada y una sola con pintura marrón, lamentablemente ninguna con diseño que ayude a relacionarla estilísticamente, pero por la pasta están más cerca de lo Colla.

\section{CHILLACORI O CHICHACCORI}

El sitio se encuentra a un costado de la carretera Macusani - Ollachea, en la margen derecha del río San Gabán, a 3082 msnm.

La superficie, sobre la que se emplazó el asentamiento arqueológico, fue aterrazado con la finalidad de elaborar recintos sobre superficies planas. Esta técnica de construcción como ya hemos notado en otros asentamientos prehispánicos del noreste puneño, se da como una solución de adaptación ante los terrenos abruptos (Fig. 15). 


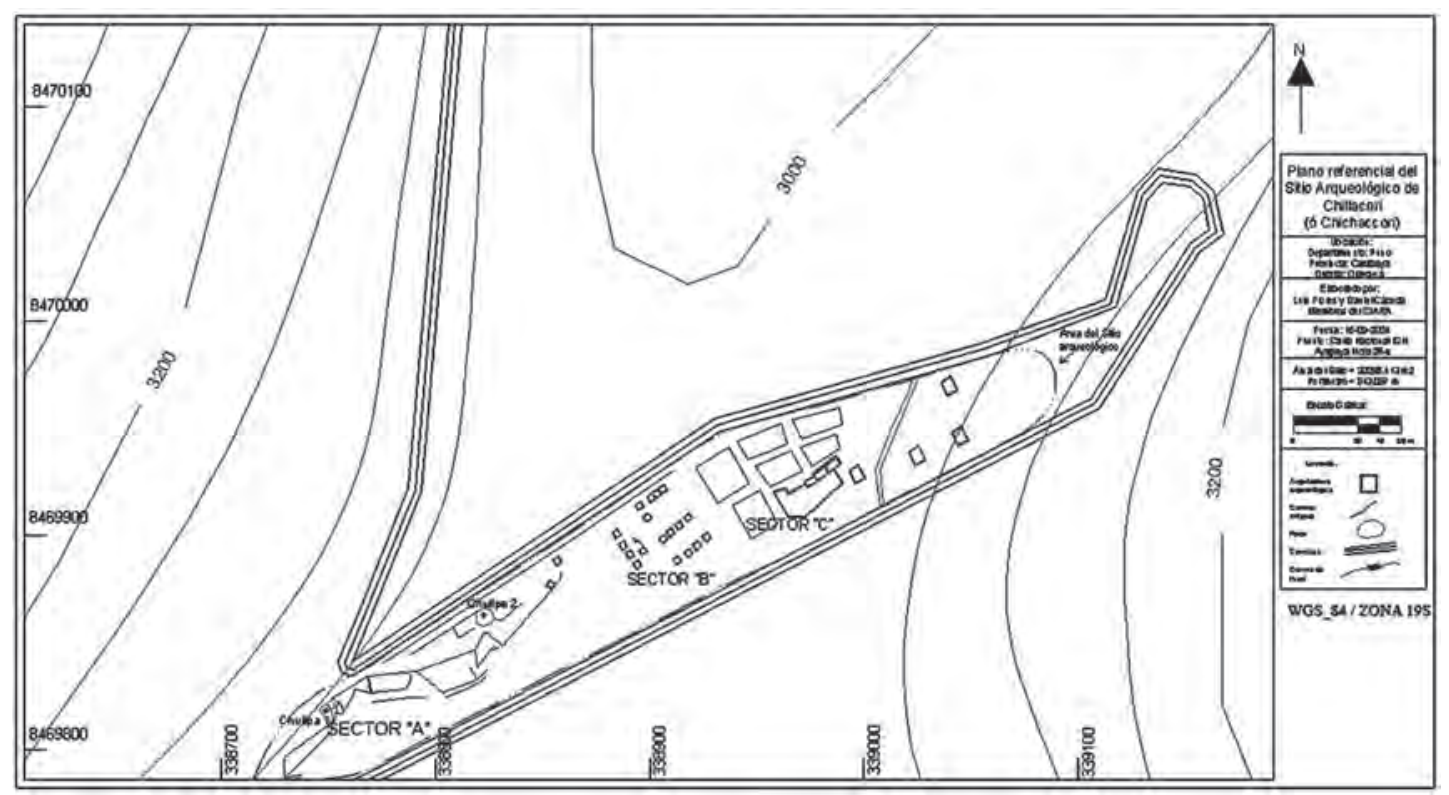

Figura 15. Plano del sitio Chichacori.

En el reconocimiento realizado se han diferenciado tres sectores, los cuales en conjunto abarcan un área de 20.098,413 $\mathrm{m}^{2}$ (un poco más de 2 hectáreas):

- Sector A. Formado por amplias plazas rectangulares que se suceden escalonadamente sobre terrazas que pueden alcanzar los $2 \mathrm{~m}$ de altura, a las cuales se acceden a través de corredores, escalinatas y vanos. Sin duda son espacios para albergar grandes concentraciones de público.

Entre las plazas sobresalen dos promontorios rocosos altos, sobre los que se levantaron chullpasi de un solo acceso. Dichas estructuras miden en promedio 1,7 $\mathrm{m}$ de lado, con muros que alcanzan hasta 1,6 $\mathrm{m}$ de altura, elaboradas con piedras cortadas unidas con un barro de color beige, mezclado con pajilla y piedrecillas. El techo es en falsa bóveda y está constituído por lajas alargadas en el interior y a partir de aquí se superponen lajas en forma de hojas, formando una cúpula sólida de piedras y barro. Estas lajas sobresalen, a manera de cornisas, unos 0,70 $\mathrm{m}$ con respecto a la pared externa. El paramento ha sido enlucido con pintura de color rojo (Fig. 16).

- Sector B. Ubicado en la parte central del asentamiento. Aquí se encuentran recintos de planta rectangular que presentan hastial (techos a doble agua), y sus muros superan lo 2,5 $\mathrm{m}$ de alto. Así mismo, hemos registrado recintos de planta semi-rectangular de menores dimensiones, pero todos dispuestos ordenadamente alrededor de patios compartidos.

- Sector C. Formado por un conjunto de grandes plazas, algunas de ellas con extensas plataformas que crean dos niveles en el interior. Las plazas están interconectadas por vanos amplios, y los muros que las separan alcanzan los 2,30 m de espesor y una altura conservada de 2,40 m.

Entre ellas se ha identificado tres recintos adosados de trazo Inka, de planta rectangular con techos a doble agua y una pequeña ventana unos centímetros por debajo del ángulo del hastial. Los accesos presentan forma ligeramente trapezoidal. El recinto más grande y central se emplaza sobre una plataforma de piedras. En el interior presenta banquetas y un pequeño espacio que se podría definir como un depósito. En la parte superior de las esquinas se encuentran cuatro lajas angulares que cumplieron una función estructural (Fig. 17).

Hacia el Oeste del recinto, descrito anteriormente, se une otro de menor dimensión, pero del mismo estilo. Su espacio interno es llano, sin ningún elemento arquitectónico adicional. 


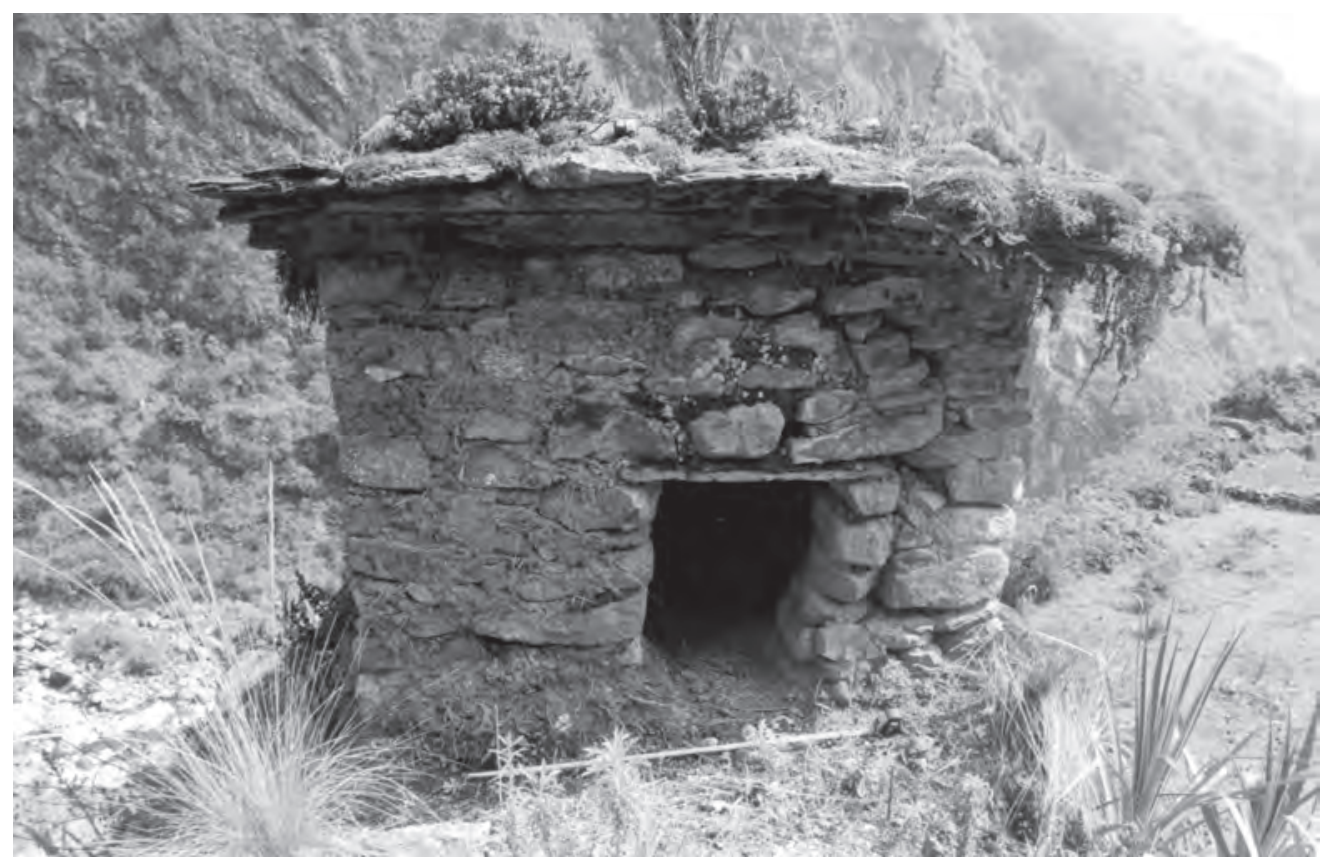

Figura 16. Una de las chullpas de Chichacori.

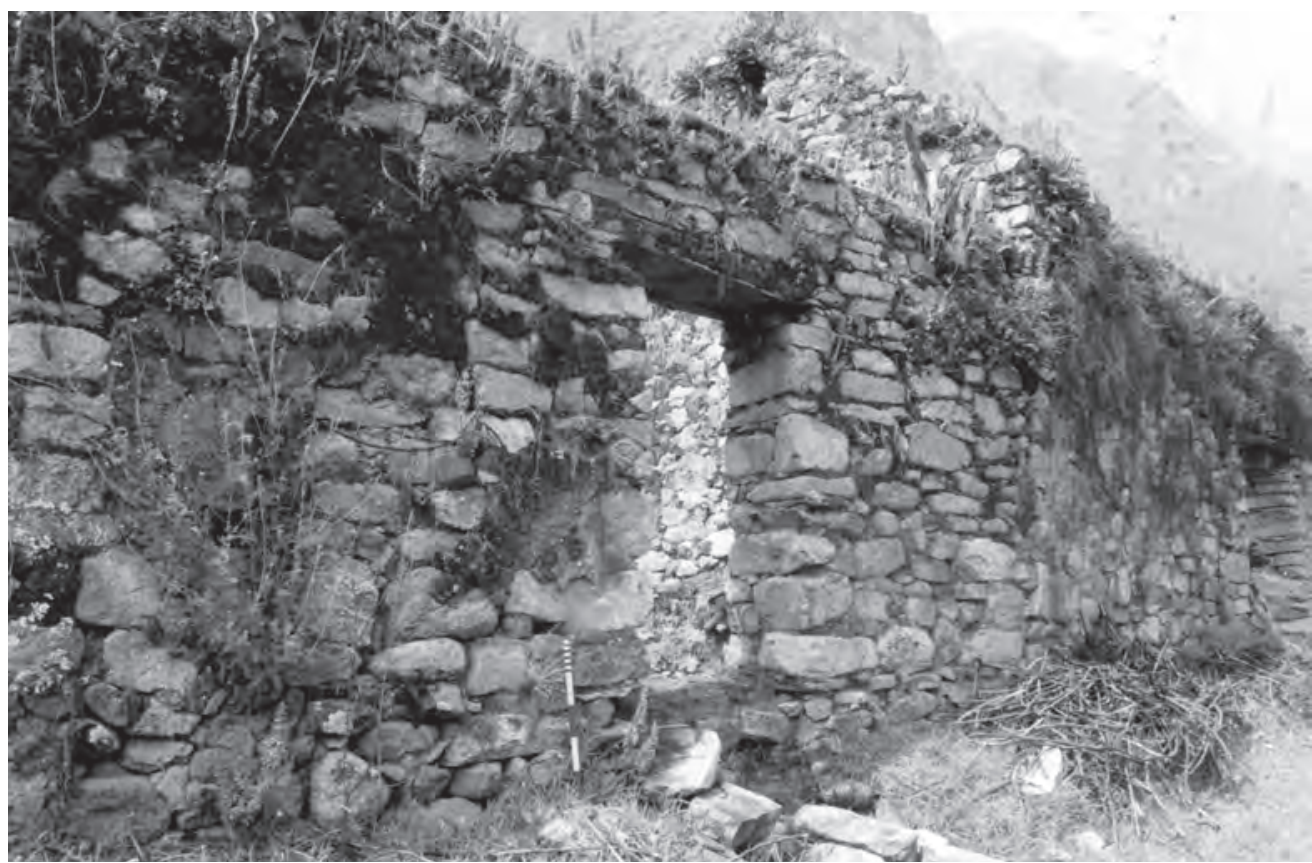

Figura 17. Recinto cuadrangular en Chichacori con vano de forma trapezoidal.

En el lado opuesto, hacia el este, se habría adosado un nuevo recinto, tiempo después de que estuvieran en funcionamiento los anteriormente descritos. Presenta banquetas en el interior y en la mitad este, una plataforma hueca que pudo funcionar como depósito. En las esquinas también se han observado cuatro lajas angulares. 
La presencia de dos chullpas y recintos, en el Sector A, similares a las que venimos identificando como una manifestación propia del los grupos del periodo Intermedio Tardío, para la región, nos estaría indicando una posible ocupación preinka, pero que al parecer sufrió una remodelación total del sitio por parte de los Inkas, tal como se pueden apreciar mejor en el Sector $C$.

Por las características de las estructuras, el manejo del espacio, una camino prehispánico que ingresa hacia el oriente y la existencia un sitio cercano (Illingaya), también vinculado con una ocupación Inka (Coben y Stanish 2005: 256-257), planteamos que estamos frente a un importante enclave incaico, asentado y remodelando un sitio del Intermedio Tardío, ubicado estratégicamente en la entrada hacia la selva, con la finalidad de controlar el comercio de productos como el oro y la coca.

\section{PITUMARCA}

Al sitio se llega luego de ascender desde el poblado Ccochauma, en la localidad de Ayapata, hasta la laguna de Ccañocota, en un tiempo aproximado de una hora, luego de pasar por una planicie donde destaca un promontorio rocoso, al pie del cual se ubica la laguna Allpicota. Sobre dicho peñón se emplaza el asentamiento arqueológico de Pitumarka, a una altitud de $4008 \mathrm{msnm}$. El sitio cubre un área de $36.752,4627 \mathrm{~m}^{2}$ (3,7 hectáreas).

En las paredes bajas del risco, sobre el que está emplazado el asentamiento, se ha registrado un conjunto de pinturas rupestres elaboradas con pigmentos de color rojo claro y anaranjado; desafortunadamente están muy alteradas por grafitis modernos y otras ya han perdido la capa pictórica, pero se pueden identificar representaciones de camélidos y de cruces (Flores y Cáceda 2004a,b).

Luego de ascender una escalinata empedrada, la entrada al sitio se da través de un vano de 1,70 m de ancho, y jambas que alcanzan los $2 \mathrm{~m}$ de espesor.

El asentamiento tiene un ordenamiento espacial, que gira en torno a una calle que parte desde el Sector A y cruza el asentamiento de Sur a Norte hasta los sectores C y D, y a partir de aquí se distribuye en tres ramales que recorren los demás sectores. Desde luego que existen calles más pequeñas que se derivan de las principales (Fig. 18).

Se han identificado 7 sectores:

- Sector A. Se trata del espacio que permite el acceso hacia el asentamiento, ubicado en el extremo sur del mismo. Es un recinto cuadrangular, de un área aproximada de $333 \mathrm{~m}^{2}$. Entre sus elementos sobresalientes se observa plataformas laterales. Por su ubicación y elementos componentes, el recinto no solo controlaba el ingreso al sitio, sino fue el espacio más importante, y mejor logrado arquitectónicamente. Detrás se suceden una serie de cuartos menores con banquetas y plataformas bajas. Creemos que este sector habría cumplido una función público ceremonial.

- Sector B. Se ubica hacia el lado norte del Sector A, y está compuesto por recintos grandes de planta rectangular, de unos $11 \mathrm{~m}^{2}$ de espacio interior, distribuidos ordenadamente en torno a una calle principal, que cruza el asentamiento. Llama la atención, que por este sector atraviesa un canal prehispánico. Por lo ordenado de la disposición de los recintos y el buen acabado arquitectónico de éstos, planteamos que estos recintos eran las residencias de la elite.

- Sector C. Está definido por los dos puntos más altos del asentamiento, sobre los cuales se han encontrado recintos contiguos de planta rectangular.

- Sector D. Recintos de planta rectangular que se disponen hacia el lado este del asentamiento, por debajo del Sector C. No muestran mucho orden en su distribución, más bien se presentan aglomerados y accesibles por estrechas callejuelas. Posiblemente estemos frente a un tipo de residencia de más bajo nivel que el del Sector $B$.

- Sector E. Aquí se encuentran seis recintos de planta rectangular, apenas separados, dispuestos en una hilera irregular. Existe un séptimo recinto que se encuentra asociado a un patio. 


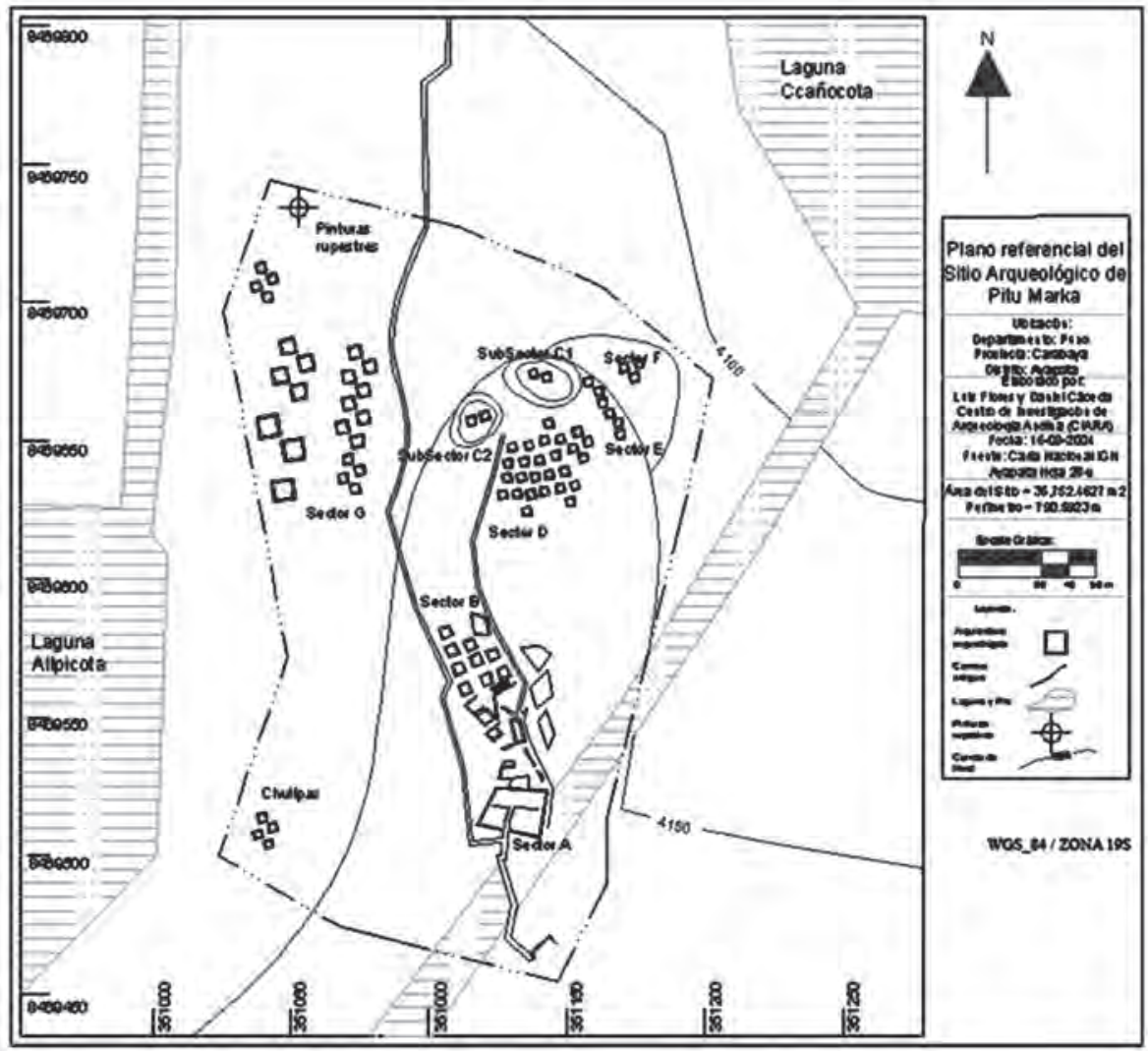

Figura 18. Plano del sitio Pitumarka.

- Sector F. Se encuentra en el extremo norte, sobre una terraza $10 \mathrm{~m}$ por debajo del Sector E. Aquí se pueden apreciar 3 o 4 recintos de planta rectangular, muy destruidos. A este sector, posiblemente se accedió desde la parte baja y no desde la cima, no habiendo identificado ninguna forma de acceso desde arriba (Fig. 19).

- Sector G. En realidad este sector esta fuera propiamente de la agrupación de los anteriores sectores. Se trata de un conjunto de recintos que se distribuyen en toda la parte baja y oeste del asentamiento, al este de la laguna Allpicota. Algunos son espacios reducidos y otros son corralones.

Además, se han observado desde lejos algunas chullpas en las cumbres de los cerros ubicados al oeste del sitio.

\section{CHULLPAS DE ESQUENA}

Se encuentran a $100 \mathrm{~m}$ de la carretera Coasa-Esquena, a unos $3694 \mathrm{msnm}$.

Las estructuras se emplazan sobre pequeños terraplenes naturales y otras se adosan a las paredes de un risco. Para acceder a ellas se debe descender desde la carretera por un abrupto terreno de pendiente muy pronunciada, que va aumentando conforme se proyecta hacia el lecho del río.

Una de las chullpas identificadas presenta planta rectangular, y techo en falsa bóveda, el cual estaba constituido por una serie de lajas planas en forma de hojuelas, que se superponen unidas con mortero de barro hasta formar una cúpula maciza. Este tipo de cubiertas ya han sido registradas para otros sitios como Chillaccori y Marca Marca III. 


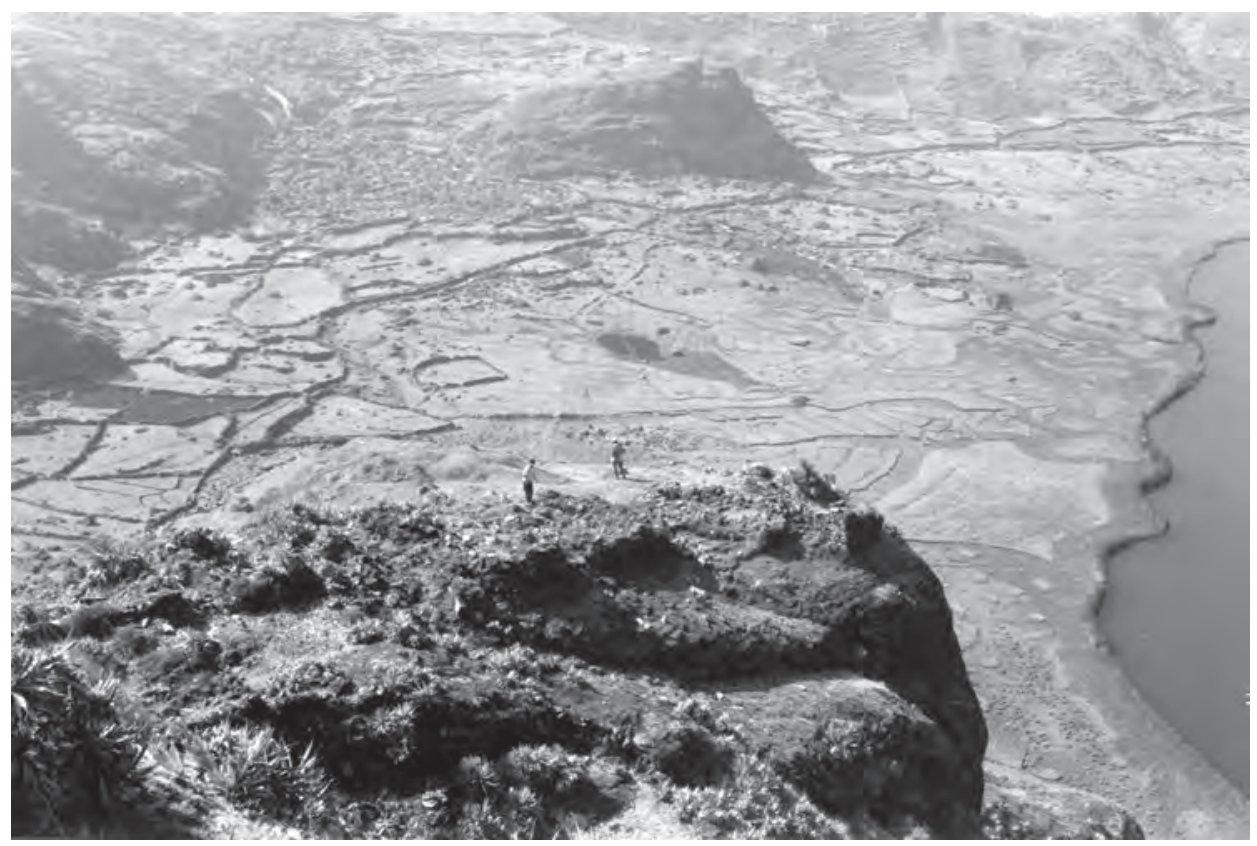

Figura 19. Vista general del sector bajo de Pitumarka. altura.

La primera chullpa que se alcanza ver estuvo pintado de rojo, y media 1,7 $\mathrm{m}$ de lado por 1,6 $\mathrm{m}$ de

Descendiendo cinco metros por los inclinados riscos, adosada a éstos, hay una cámara funeraria múltiple, muy destruida por la actividad de huaqueo y por los movimientos sísmicos que han resquebrajado gran parte de la roca que la soporta. En el interior existen cuatro compartimientos en los cuales se depositaron fardos funerarios, que según la evidencia de superficie estaba constituidos por individuos de ambos sexos, cada uno con ofrendas asociadas como vasijas de cerámica.

Al frente de estas chullpas, en la otra margen de la quebrada, se observa un asentamiento arqueológico llamado Huatamarca, que no pudimos visitar, pero que los pobladores locales lo describen como un sitio extenso y de buen acabado, a dos horas de camino del pueblo de Esquena. Ávila (2005: 108) señala que en este sitio existen chullpas de doble piso.

\section{MARKA MARKA III}

Se encuentra en la cresta de un cerro, a unos 3883 msnm, en la margen izquierda del río Pacchani, al frente del pueblo de Usicayos, a una hora de camino (Fig. 20).

El asentamiento se orienta de Oeste a Este, y está presidido por un complejo sistema de andenes que se extienden desde la cima hasta el lecho de la quebrada. El sitio es atravesado por un camino antiguo, el cual en algunos tramos se conserva empedrado. Dicha vía ingresa por el suroeste, entre los andenes, y va ascendiendo hasta llegar a una plaza, para luego seguir su trayecto con dirección noroeste hacia el actual distrito de Coasa. El área total del sitio, incluyendo buena parte de los andenes, es de 259.413,5334 $\mathrm{m}^{2}$ (casi 26 hectáreas), pero sólo el conjunto arquitectónico es de 69.316,9436 $\mathrm{m}^{2}$ (cerca de 7 hectáreas) (Fig. 21).

En el aspecto formal, los recintos son de planta rectangular y están dispuestos sobre terrazas. El material constructivo está constituido por piedras alargadas, toscamente careadas, asentadas sobre mortero de barro. No se han observado diferencias en cuanto a la técnica constructiva, ni en la forma 


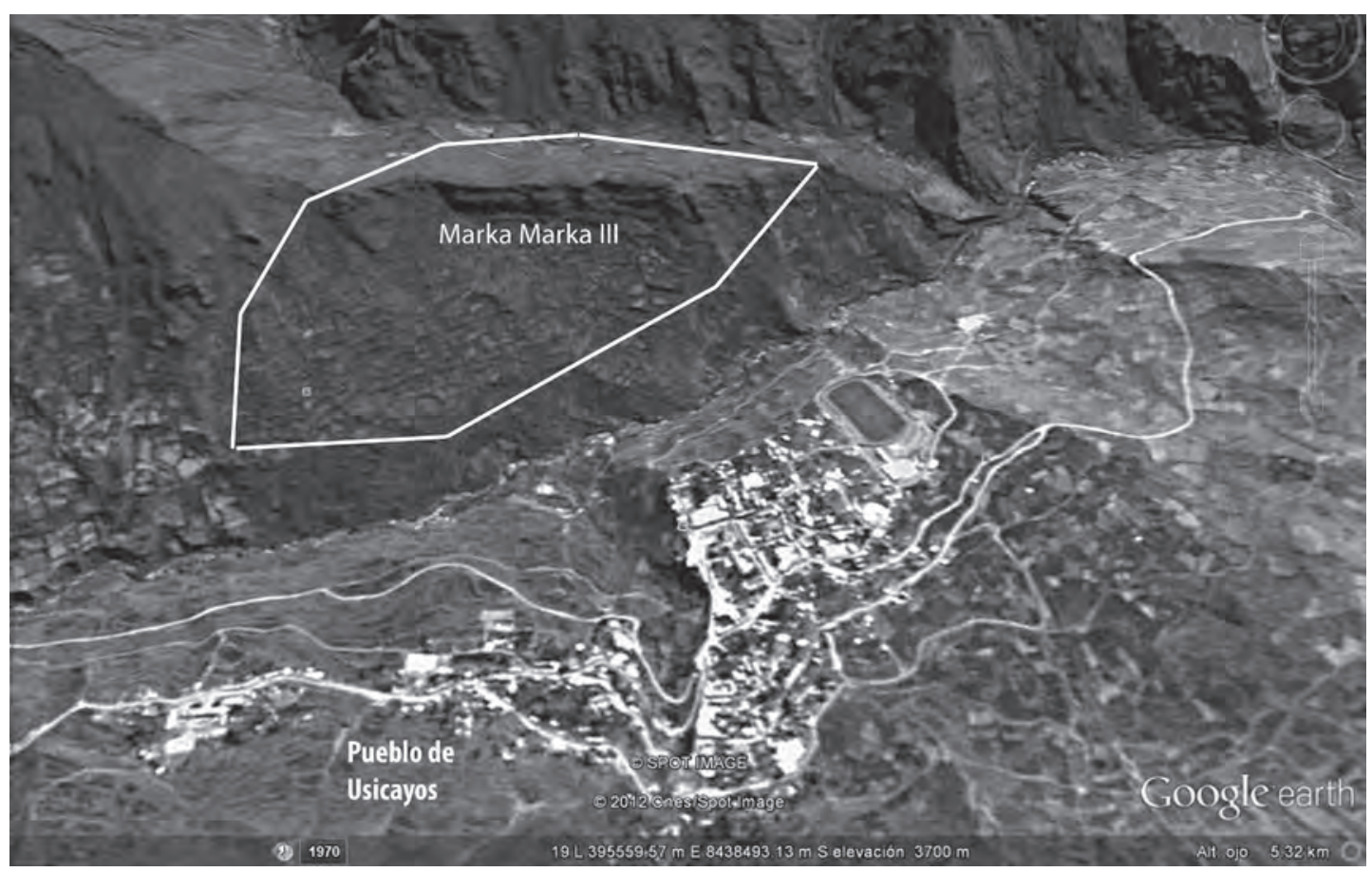

Figura 20. Vista satelital del conjunto Marka Mark III.

de los edificios, salvo el caso del Sector A, que nos recuerda a los sitios del Intermedio Tardío. Esta homogeneidad constructiva, en la mayor parte del sitio, y su estilo constructivo, estaría reflejando que el sitio es fundamentalmente Inka.

En el sitio se han podido identificar siete sectores, articulados entre sí por una serie de calles y pasajes, que se desprenden de una principal que cruza el asentamiento de este a oeste. Dichos sectores son los siguientes:

- Sector A. Está constituido por estructuras del tipo chullpas, ubicadas en la parte baja y norte del asentamiento, a lo largo del camino que se dirige hacia el distrito actual de Coasa.

Formalmente tienen planta rectangular, de 1,3 a 1,7 m de lado por 1,5 a 1,8 $\mathrm{m}$ de alto, mas $1 \mathrm{~m}$ de altura del techo cupular. Fue construida a base de piedras alargadas, asentadas en barro con pajilla y pintadas primero de amarillo y luego de rojo.

En el interior de algunas de las chullpas se dispusieron dos lajas en posición transversal, que funcionaron como repisas, posiblemente para colocar ofrendas a los cuerpos que albergaba.

- Sector B. Se encuentra en la parte más extrema y alta del sitio, hacia el Oeste. Desde esta posición se domina todo el asentamiento, el río y la andenería en la parte baja. Además se han identificado hasta tres pequeños espacios, que parecen ser posiciones de observación o vigilancia.

- Sector C. Este sector se ubica al este del Sector B, y está constituido por un conjunto de estructuras como terrazas y pequeños recintos, asociados a la plaza 2.

- Sector D. Ubicada hacia el noreste del Sector C, está constituido por grandes recintos de planta rectangular que se disponen concentradamente, uno junto al otro, y asociados a patios. Los recintos presentan hastial y en algunos casos ventanas, accesos y hornacinas de forma trapezoidal y muros que superan los $3 \mathrm{~m}$ de altura (Fig. 22). 


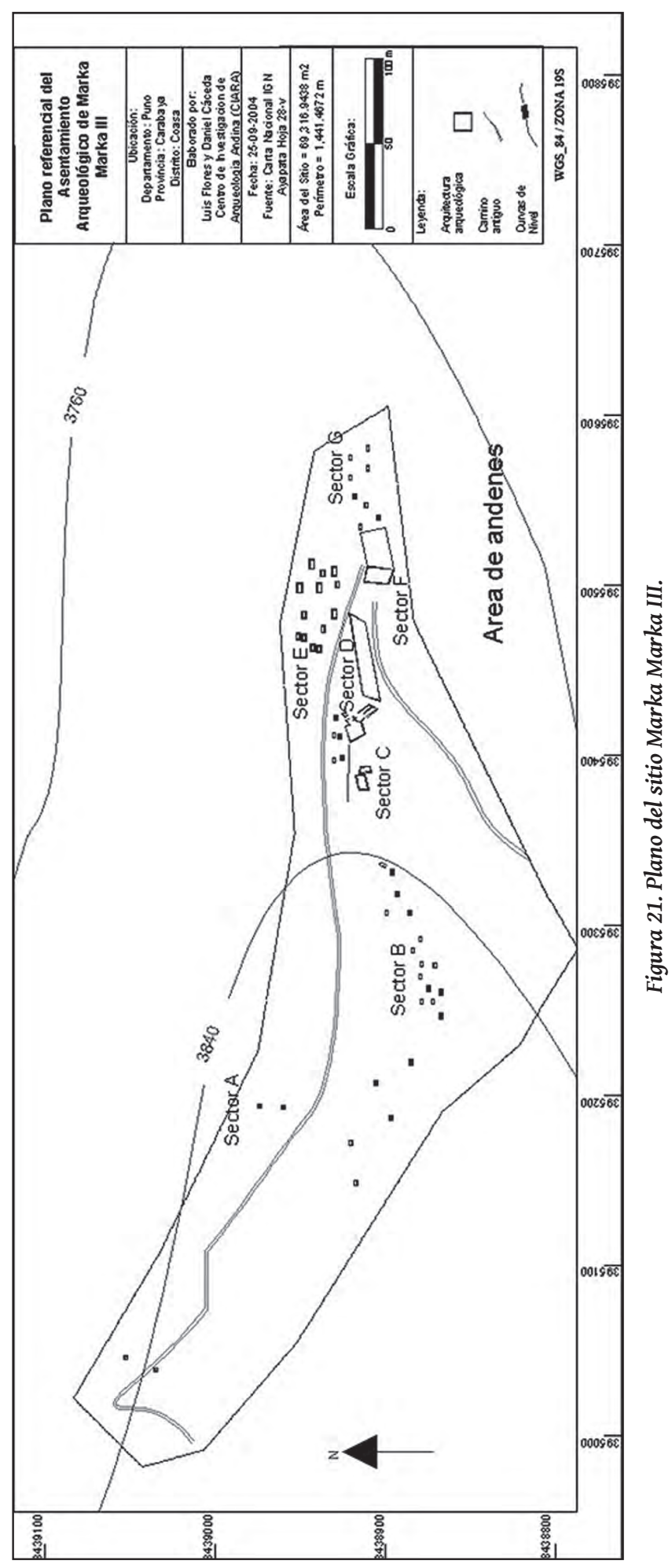




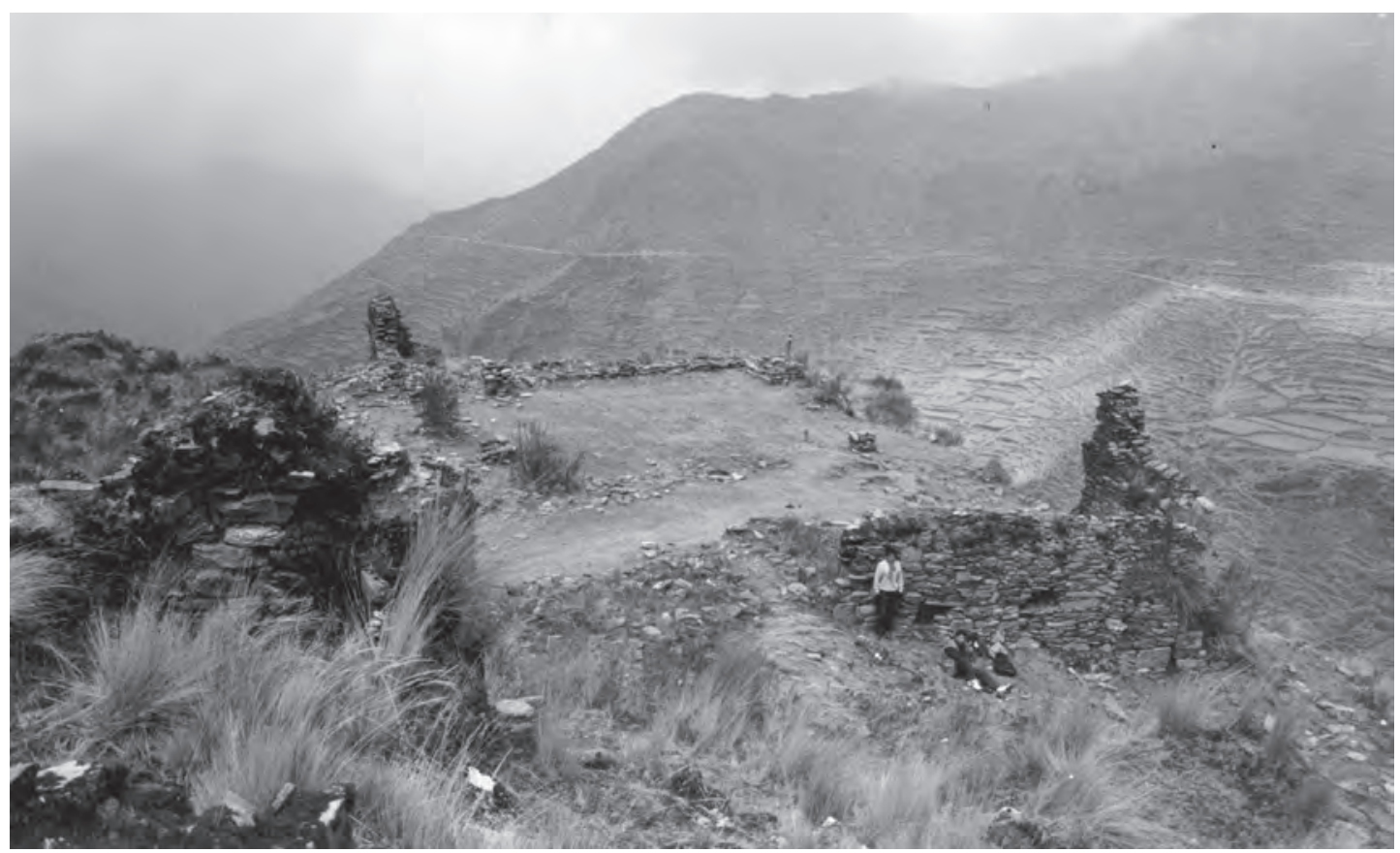

Figura 22. Vista del ingreso al sitio Marka Marka III.

- Sector E. Abarca todo el flanco noreste del sitio. Se observan recintos de menores dimensiones, en mayor número que los existentes en el Sector D, pero que guardan un ordenamiento en el manejo y distribución del espacio. Están asociados a la calle principal que atraviesa el asentamiento de este a oeste.

- Sector F. Es una plaza con dos recintos laterales, uno a cada lado y orientados frente a frente. Estos recintos presentan planta rectangular y hastíales, y en su interior se distribuyen hornacinas de forma trapezoidal.

El camino antiguo que asciende desde el río Pacchani ingresa por el lado sur de esta plaza, por lo que todo aquel que recorría esta ruta debía de obligatoriamente ingresar a esta asentamiento; entonces su ubicación es estratégica, ejerciendo el control del tránsito hacia la actual Coasa.

- Sector G. Es el conjunto de terrazas y recintos de mayor aglutinamiento, que se disponen hacia el extremo Este del asentamiento.

\section{OTROS SITIOS ARQUEOLÓGICOS EN CARABAYA}

Existen otros sitios que se han reportado, Illingaya en Ollachea, Oja T'Oqo en Ituata; Khurkutra, Qoa Qoa en Coaza; Phushka, Oqosiri, Sucho Ccucho, Phichu y Phisca Puncu en Usicayos (Ávila 2005: 108109; Dueñas 1975: 20).

\section{La ocupación en los Paisajes de SANDia y CaRABaya}

Como se desprende de la descripción hecha de cada uno de los sitios, el patrón de asentamiento de los yacimientos de Sandia y Carabaya privilegia su ubicación en ladera alta o en la cima de alguna montaña, seguramente para tener una gran cuenca de visibilidad como estrategia de control. 
Para comprobar esta hipótesis realizamos un análisis de visibilidad (viewshed) computarizada, desde un programa que permita analizar el espacio en el marco de un Sistema de Información Geográfica. $^{2}$

En este caso solo escogimos trabajar con los sitios de Sandia, que son los más completos que tenemos para una sola cuenca; el trabajo en Carabaya fue más extensivo, y por lo mismo abarcamos más espacio, pero registramos pocos sitios contiguos.

Los resultados de este análisis en Sandia fueron interesantes, casi todos los sitios tenía una gran visibilidad (Fig. 23), especialmente de las partes bajas, de las pocas tierras cultivables en el valle y del rio, así como obviamente de los caminos. A partir de nuestra muestra, y sin saber si existen otros sitios intermedios, casi podemos asegurar que entre sitios más cercanos podían observarse.

El único asentamiento que no sigue este patrón es Colo-Colo, pero ello puede explicarse porque está ubicado en un pequeño valle, mucho más encajonado que el Sandia; pero más allá de razones topográficas, es debido a que estamos frente a un lugar que al parecer es funerario, sin descartar su uso habitacional o ritual, por lo cual la lógica de visibilidad es otra, la de un espacio sacralizado, donde el factor que incidió para su ubicación fue el de ser visible desde ciertos puntos, y no tanto tener una amplia visibilidad desde ella, como si reflejan los asentamientos poblacionales. Habría que analizar posteriormente Colo-Colo, al igual que otros sitios funerarios, desde dicha lógica, tal como lo han hecho en otros lugares (Criado 1984-85).

Otro tema aquí relevante, y que refuerza la importancia del control visual, es el manejo de los caminos, claros ejemplos de ello son los sitios de Chichacori, Marka Marka III, Quilli Quilli, Chunchulacayoc y los otros. Por todo ello, es evidente la ubicación estratégica de los sitios con fines de control económico y político.

Si algo queda claro, es que la región fue muy importante para el sistema económico, tanto para las culturas pre-incas, Incas y para los españoles, por sus recursos naturales como los metales preciosos (especialmente el oro) y las especies exóticas; ello explicaría el por qué toda la región estaba comunicada a través de una red de caminos antiguos que unen sierra y selva. Sin embargo, habría que investigar más otro factor, más allá del sistema económico hay un sistema simbólico, en búsqueda de objetos exóticos para las elites Collas e Incas, tan necesario para consolidar su ostentación de poder. Tal vez una materialización de ello sea la aparición de megalíticas tumbas.

\section{LA PRESENCIA DE LAS CHULLPAS EN EL PAISAJE}

Las sociedades están relacionadas con su medio ambiente, construyendo un paisaje con significados para su mundo, para ello se han valido de diferentes elementos que expresan sus ideas, una de ellas fue la forma de manejar su tumba, como forma de manipular su historia.

Nosotros creemos que en estas regiones estudiadas, las chullpas han jugado un papel importante para monumentalizar el paisaje, pero al mismo tiempo para expresar un sistema de ideas, que si bien hoy para nosotros es inentendible, para ellos estuvo lleno de significado, tanto para los que lo construyeron, como para las sociedades vecinas; porque formó parte de su sistema ideológico de poder (Bradley 1993; Gil 2002). Por ello, las chullpas deben ser entendidas más eclécticamente, como símbolos territoriales que son asimismo socialmente activos (Criado 1989: 78)

2 Para este trabajo nos valimos de ArcGis 10. Hay que precisar que realizamos una análisis muy rápido, sin tener en cuenta la altura del observador, lo cual nos pudo haber dado una mayor cuenca; sin embargo para los propósitos de solo tener una idea de la visibilidad desde los sitios, este análisis fue suficiente. Para ello, usamos el instrumento de análisis espacial de superficie Viewshed, sobre un raster de un MDT de la región y los datos georefenciados (en WGS-84) de los sitios registrados en Sandia (sin considerar Cuyo Cuyo, por tratarse de un paisaje cultural, y no un sitio ocupacional). 
De esta forma, la ubicación de las chullpas, siempre en el lugar más visible, más prominente; es una forma clara de mostrar su identidad, pero también de ostentar su grandeza, de dar un mensaje a su sociedad, de manera pública.

Pero hay una particularidad que nos gustaría explicar. Es interesante notar la escasez de chullpas cuando están dentro de un asentamiento (ej. Chichacori y Maukallacta), y su relativa abundancia cuando son sitios independientes (ej. Colo-Colo y Huancasayan). Obviamente estos eran sitios para notables, porque, en cualquier de los casos, no permitía una capacidad, ni remotamente suficiente, para albergar a toda la población.

En el primer caso, dentro de los sitios, como en Chichacori, era una forma clara de relacionarlos con sus antepasados comunes, y con ello ligarlos, justificándolos, a la tierra. En el segundo caso, como sitios independientes, las chullpas fueron la demostración de un terreno ganado, expropiándola con el ritual sacro.

En nuestro lógica, tratándose de grupos controlando verticalmente el territorio, Collas y luego Incas, requieren de justificantes ideológicos para ello, una especie de bandera que fije su territorio, para poder tener el derecho de extraer las riquezas de la tierra. Un adicional a todo esta estrategia, fue la gran concentración de pinturas rupestres a lo largo de la región.

En ambos casos, siempre las chullpas estaban asociados a plazas construidas o alrededor de espacios abiertos. Por todo ello, es evidente la importancia del ritual, la fiesta y el banquete en el pase y la vida de los antepasados, algo que se ha venido planteando para los Andes (Isbell 1997; Kaulicke 1997).

Por todo ello, como ha señalado Hyslop (1977), la construcción de la chullpa marcó una gran transformación religiosa y cultural luego de Tiwanaku.

\section{Filiación CULTURAL Y CRONOLÓGICA DE LOS Sitios}

Otro tema, que resulta aun problemático para la región, es establecer incluso tentativamente, la filiación cultural de los sitios de Sandia y Carabaya. En nuestro caso debido al tipo de reconocimiento tan superficial que realizamos, la escasa cerámica observada, pero sobre todo la casi nula información arqueológica sobre estas regiones.

Hasta hace poco nos preguntábamos (Flores et al. 2012) ¿Quiénes habían sido los constructores de estas evidencias prehispánicas, habría sido población local del oriente puneño o grupos de avanzada venida del Altiplano para aprovechar los diferentes pisos ecológicos que proporciona el territorio?

Sin embargo, a partir de estos pocos datos y por las semejanzas constructivas, como la presencia de un único tipo de chullpas, que en la tipología de Marion Tshopik (1946: 15-16) sería el Tipo 3, la presencia de cerámica típica Colla e Inca (Flores et al. 2012) y arte rupestre que se puede asociar estilísticamente también a dichos periodos tardíos (Flores y Cáceda 2004b); podemos atrevernos a plantear primero que la mayoría de los sitios descritos pertenecen originalmente al periodo Intermedio Tardío o Altiplano, y que estuvieron relacionado al desarrollo de un amplio territorio Colla. Pero que luego, algunos de ellos fueron vueltos a ocupar y ampliados por la avanzada Inca, en un aprovechamiento político-económico vertical, similar a lo propuesto por Murra (1975).

Para la primera afirmación, hay que tener en cuenta que los lingüistas incluyen a la zona noroeste, norte y noreste del altiplano como el área de distribución del habla puquina, por tanto asociado al grupo cultural Colla (Torero 1987, 2005). Además, recientes datos evidencian sitios con cerámica Colla, a lo largo del rio Ollachea, en Carabaya (Román y Román).

Para la segunda, creemos que sigue teniendo mayor claridad la presencia Inca en la zona. Hemos registrado elementos arquitectónicos de características Inka, y cerámica distintiva cusqueña, muchos de ellos superpuestos a evidencias del Intermedio Tardío o Altiplano en Chillacori, Quilli-Quilli y 


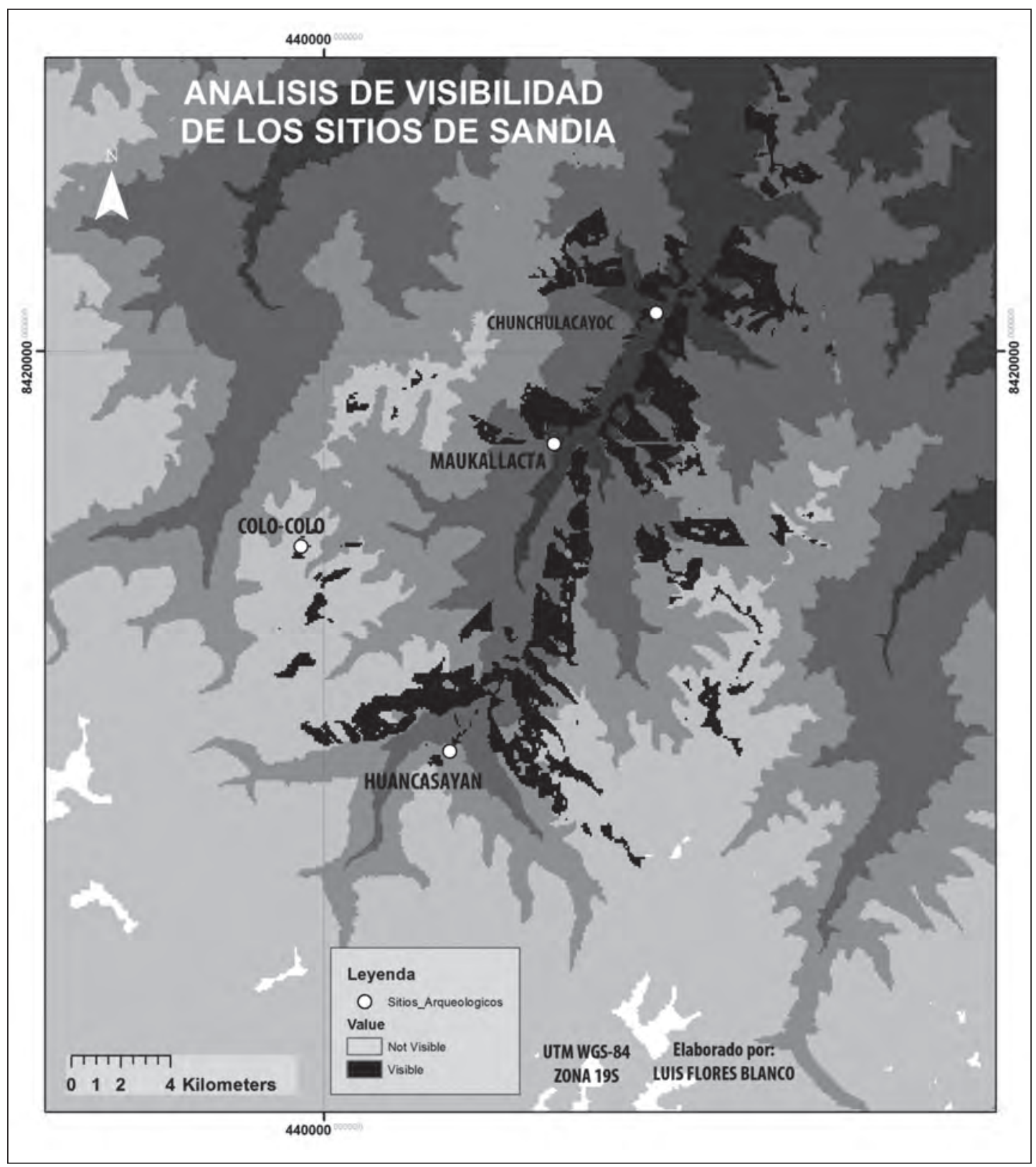

Figura 23. Plano de análisis de visibilidad de los asentamientos de Sandia.

Marca Marca de Tantamaco (en Carabaya) y posiblemente en Maukallacta en Sandia. Recientemente, también cerámica Inca imperial, pero también cerámica doméstica, ha sido reportada a lo largo de Ollachea (Román y Román 2012).

Todos estos planteamientos, sobre cronología y corología son todavía preliminares, sólo prospecciones sistemáticas y futuras excavaciones arqueológicas podrán caracterizar la arqueología del norte de Puno. Esperamos que los recientes trabajos en la región (Román y Román 2012; Vega-Centeno 
2000) sean pronto publicados extensivamente. Desafortunadamente, hay que decirlo, la región de Sandia sigue quedando relegada de investigaciones.

\section{Agradecimientos}

Este articulo es el fruto de un esfuerzo conjunto de un grupo de arqueólogos, que en ese entonces nos reunimos en el Centro de Investigación de Arqueología Andina (CIARA). El apoyo logístico y económico se lo debemos a las autoridades locales de aquel entonces, durante 2004. Quedamos agradecidos con el Dr. Enrique Quilla Gómez y su teniente-alcalde Luis Cabrera Cárdenas de la provincia de Sandia. Por la parte de Carabaya, quedamos eternamente agradecidos con el entonces alcalde Sr. Michel Portier Ballano, y su teniente-alcalde Julio Juno Minaya, así como los señores Nilo Maque Huayta y el profesor Nicolás Luna Peralta; todos ellos, en todo momento, estuvieron prestos a ayudarnos. Su preocupación constante por su historia local nos hizo sentir en casa y con deseos de volver.

\section{BiBLIOGRAFÍA}

AVILA QUISPE, Walter M.

2005 Carabaya. Historia General. Tomo I. 310 p.

BRADLEY, R.

1993 Altering the Earth. The origins of monuments in Britain and Continental Europe. Edimburgo: Society of Antiquaries of Scotland.

COBEN, Lawrence y Charles STANISH

2005 Archaeological Reconnaissance in the Carabaya Region, Peru. En Advances in Titicaca Basin Archaeology-1, pp. 243-266

CONLEE, C., J. DULANTO, C. MACKEY y C. STANISH

2004 «Late Prehispanic Sociopolitical Complexity». En: Silverman (ed.) Andean Archaeology, pp. 209-236. Blackwell Publishing Ltd.

CORNEJO, Cesar y Luis FLORES

2004 Evaluación Preliminar del Potencial Científico y Turístico de los Principales Monumentos Arqueológicos de La Provincia de Sandia. Informe Final presentado a la Municipalidad Provincial de Carabaya. Ms.

CRAIG, N., R. J. SPEAKMAN, R. S. POPELKA-FILCOFF, M. ALDENDERFER, L. FLORES BLANCO, M. BROWN, M. D. GLASCOCK Y C. STANISH

2010 «Macusani obsidian from southern Peru: A characterization of its elemental composition with a demonstration of its ancient use». Journal of Archaeological Science 37: 569-576.

CRIADO BOADO, Felipe

1984-5 ««El Tercer Factor» o la lógica oculta del emplazamiento de los túmulos megalíticos gallegos». Separata de «Cuaderno de Estudios Gallegos». Vol. XXXV - N 100: 7-12.

1989 «Megalitos, espacio, pensamiento». Trabajos de Prehistoria 46: 75-98. Madrid.

DUEÑAS TOVAR, Benjamín

1975 Ensayo Monográfico de la provincia de Carabaya. Puno: Editorial Los Andes.

FLORES, Luis y CACEDA, Daniel

2004a «Arte Rupestre en la Provincia de Carabaya, Puno: Estableciendo una secuencia temporal relativa». Ponencia presentada el I Simposio Nacional de Arte Rupestre llevado a cabo en Cusco en Noviembre del 2004.

2004b Evaluación del Potencial Científico y Turístico de los Principales Recursos Culturales de la Provincia de Carabaya, Puno. Informe Final presentado a la Municipalidad Provincial de Carabaya. Ms.

FLORES, Luis, Cesar CORNEJO y Daniel CACEDA

2012 «The Archaeology of Northern Puno: Late Sites in Sandia and Carabaya, Peru». En: A. Vranich, E. Klarich y C. Stanish (eds.) Advances in Titicaca Basin Archaeology - III, pp. 265-281. Memoirs of the Museum of Anthropology, University of Michigan, Number 51. 
FLORES, Luis y Henry TANTALEAN (eds.)

2012 Arqueología de la cuenca del Titicaca, Perú. Lima: IFEA-COTSEN.

FRANCO INOJOSA, José María

1936 «Exploraciones Arqueológicas en el Perú: Departamento de Puno». En: Revista del Museo Nacional. Tomo V, № 2: 157-183, Lima.

GARCILASO DE LA VEGA, Inca

2005 Comentarios reales de los incas. Tomos I y II. Edición y prologo de Carlos Araníbar. Tercera reimpresión, Lima: Fondo de Cultura Económica.

GIL, Francisco M.

2002 «Acontecimientos y regularidades chullparias: más allá de las tipologías. Reflexiones en torno a la construcción del paisaje chullpario». Revista Española de Antropología Americana 32: 207-241.

GUAMAN POMA DE AYALA, Felipe

2005 [1615] Nueva Corónica y Buen Gobierno (obra completa). Edición y prólogo de Franklin Pease. Lima: Fondo de Cultura Económica.

HODGE, WH

1951 «Three native tuber foods of the high Andes». Economic Botany 5 (No. 2): 185-201.

HOSTNIG, Rainer

2003a «Macusani, depositario de arte rupestre milenario en la Cordillera de Carabaya, Puno - Perú». En: Boletín SIARB, № 17: 17-35, Octubre, Sociedad de Investigación del Arte Rupestre de Bolivia (SIARB). La Paz.

2003b Arte Rupestre del Perú. Inventario Nacional. Lima: CONCYTEC.

2004 «Las maravillas de Macusani y Corani». En RUMBOS, año IX, nº 40.

2010 Carabaya, Paisajes y Cultura Milenaria. Municipalidad provincial de Carabaya.

HYSLOP, John

1977 «Chulpas of the Lipaca Zone of the Peruvian High Plateau». Journal of Field Archaeology 4(2): 129-170.

ISBELL, William

1968 «New discoveries in the montaña of southeastern Peru». Archaeology 21(2): 108-114.

1997 Mummies and mortuary monuments. A postprocessual prehistory of central Andean social organization. Austin: University of Texas Press.

JACKSON, Mike T.

2012 The agricultural terraces of Cuyo Cuyo, southern Peru. [En línea] Disponible en <http://mikejackson1948.wordpress.com/2012/03/13/the-agricultural-terraces-of-cuyo-cuyo-southern-peru/> [acceso el 18 de enero de 2013].

JACKSON, M. T., J. G. HAWKES y P. R. ROWE

1980 «An ethnobotanical field study of primitive potato varieties in Peru». Euphytica 29: 107-113.

KAULICKE, Peter

1997 «La Muerte en el Antiguo Perú. Contextos y conceptos funerarios: una introducción». Boletín de Arqueología PUCP 1: 7-54.

NALVARTE MALDONADO, Nicolás

1983 «Panorama turístico de la Provincia de Sandia». En: Frisancho Pineda (ed.) Álbum de Oro, Tomo X, pp. 119-130. Puno.

NEIRA AVENDAÑO, Máximo

1967 «Informe preliminar de las investigaciones arqueológicas en el departamento de Puno». Anales del Instituto de Estudios Socio Económicos 1 (1). Puno: Universidad Técnica del Altiplano.

NORDENSKIÖLD, Erland

1953 Investigaciones arqueológicas en la región fronteriza de Perú y Bolivia. Upsala / Estocolmo (1906); Biblioteca Paceña. Alcaldía Municipal, La Paz

LÓPEZ, Segisfredo

2012 «El Sistema Vial en la Región de Puno». En: Luis Flores y Henry Tantaleán (eds.), Arqueología de la cuenca del Titicaca, Perú. pp. 385-427. Lima: IFEA - COTSEN. 
LUNA PERALTA, Nicolás

1999 Ensayo monográfico del Distrito de Corani-Carabaya. Macusani:Editorial Área del Desarrollo EducativoEnlace, Macusani. $41 \mathrm{p}$.

MURRA, Jhon V.

1975 Formaciones económicas y políticas del mundo andino. Lima: IEP.

PALAO BERASTAIN, Juan B.

1991 «Arte Rupestre pictórico de Tantamayo - Puno, Perú». [Resumen]. Ms., 9 p., 1 mapa, 1 foto, 6 dibujos. Inédito.

PEISA ediciones

2004 Tomo 7: Puno. En Atlas Regional del Perú. Imagen geográfica, estadística, histórica y cultural. Lima-Perú, $112 \mathrm{p}$.

RAIMONDI, Antonio

1874 El Perú. Parte Preliminar (Tomo I). Libro segundo, cap. V: 177-202. Lima: Imprenta del Estado.

1887 Minas de oro del Perú. Lima: Impr. y Libr. B. Gil.

ROMÁN, Nancy y Silvia ROMÁN

2012 «Patrón funerario de los períodos Altiplano e Inca en el valle de Ollachea, Carabaya - Puno». En: Luis Flores y Henry Tantaleán (eds.) Arqueología de la cuenca del Titicaca, Perú, pp. 321-337. Lima: IFEA - COTSEN.

QUISPE ARAGON, Amador; QUISPE ARAGON, Lorgio V y QUISPE ARAGON, José

1995 Macusani. Capital de la Provincia de Carabaya. Macusani-Puno. 177 p.

SPAHNI, J.C.

1971 Semblanza de los pueblos del Perú. Lima: Peruano Suiza S.A.

STANISH, Charles

2003 Ancient Titicaca. The Evolution of Complex Society in Southern Peru and Northern Bolivia. University of California Press. 354 p.

TAPIA, Félix

1985 Contribución a la investigación arqueológica en los valles de Sandia y Carabaya, en el departamento de Puno - Perú. Puno: Grupo de Arte Utaraya.

TSCHOPIK, Marion H.

1946 Some Notes on the Archaeology of the Department of Puno, Peru. Papers of the Peabody Museum of American Archaeology and Ethnology, Harvard University Vol. XXVII, № 3. Cambridge, Massachusetts, USA. 57 p.

214 TORERO, Alfredo

1987 «Lenguas y Pueblos Altiplánicos en torno al Siglo XVI». Revista Andina Año 5, № 2. Cusco.

2005 Idiomas de los Andes. Lingüística e Historia. Lima: IFEA y Editorial Horizonte, Lima, 2da edición.

VEGA-CENTENO, Patricia

2009 «Investigación arqueológica para el registro de sitios con arte rupestre en los distritos de Macusani y Corani, Provincia de Carabaya, Puno». Boletín APAR, Boletín oficial de la Asociación Peruana de Arte Rupestre, 1(1): 5. 